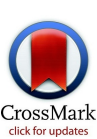

click for updates

\title{
Efficacy and effectiveness of screen and treat policies in prevention of type 2 diabetes: systematic review and meta-analysis of screening tests and interventions
}

\author{
Eleanor Barry, ${ }^{1}$ Samantha Roberts, ${ }^{1}$ Jason Oke, ${ }^{1}$ Shanti Vijayaraghavan, ${ }^{2}$ Rebecca Normansell, ${ }^{3}$ \\ Trisha Greenhalgh
}

$\overline{{ }^{1} \text { Nuffield Department of Primary }}$ Care Health Sciences, Radcliffe Primary Care Building, Radcliffe Observatory Quarter, University of Oxford, Oxford OX2 6GG, UK 2Department of Diabetes, Newham University Hospital, Barts Health NHS Trust,

London, UK

${ }^{3}$ Population Health Research Institute, St George's University of London, London SW17 ORE, UK

Correspondence to: E Barry Eleanor.barry@phc.ox.ac.uk

Additional material is published online only. To view please visit the journal online.

Cite this as: $B M J$ 2017;356:16538 http://dx.doi.org/10.1136/bmj.i6538

Accepted: 28 November 2016

\section{ABSTRACT}

OBJECTIVES

To assess diagnostic accuracy of screening tests for pre-diabetes and efficacy of interventions (lifestyle or metformin) in preventing onset of type 2 diabetes in people with pre-diabetes.

DESIGN

Systematic review and meta-analysis.

\section{DATA SOURCES AND METHOD}

Medline, PreMedline, and Embase. Study protocols and seminal papers were citation-tracked in Google Scholar to identify definitive trials and additional publications. Data on study design, methods, and findings were extracted onto Excel spreadsheets; a $20 \%$ sample was checked by a second researcher. Data extracted for screening tests included diagnostic accuracy and population prevalence. Two metaanalyses were performed, one summarising accuracy of screening tests (with the oral glucose tolerance test as the standard) for identification of pre-diabetes, and the other assessing relative risk of progression to type 2 diabetes after either lifestyle intervention or treatment with metformin.

\section{ELIGIBILITY CRITERIA}

Empirical studies evaluating accuracy of tests for identification of pre-diabetes. Interventions (randomised trials and interventional studies) with a control group in people identified through screening. No language restrictions.

RESULTS

2874 titles were scanned and 148 papers (covering 138 studies) reviewed in full. The final analysis included 49

\section{WHAT IS ALREADY KNOWN ON THIS TOPIC}

Type 2 diabetes is increasingly common; its prevention is an international health priority

There is no agreement on how best to define or detect "pre-diabetes" (that is, high risk of developing type 2 diabetes in the future)

Trials in people with pre-diabetes have shown that the onset of type 2 diabetes can be delayed or prevented with lifestyle measures or metformin

\section{WHAT THIS STUDY ADDS}

This is the first systematic review to assess both the diagnostic accuracy of screening tests for pre-diabetes and the efficacy of interventions in those detected by screening As different tests for pre-diabetes define vastly different populations, large numbers of people will be unnecessarily treated or falsely reassured depending on the test used

"Screen and treat" policies will benefit some but not all people at high risk of developing diabetes; they might need to be complemented by population-wide approaches for effective diabetes prevention

studies of screening tests (five of which were prevalence studies) and 50 intervention trials. $\mathrm{HbA}_{1 \mathrm{c}}$ had a mean sensitivity of 0.49 ( $95 \%$ confidence interval 0.40 to 0.58 ) and specificity of 0.79 ( 0.73 to 0.84 ), for identification of pre-diabetes, though different studies used different cut-off values. Fasting plasma glucose had a mean sensitivity of 0.25 ( 0.19 to 0.32 ) and specificity of 0.94 (0.92 to 0.96). Different measures of glycaemic abnormality identified different subpopulations (for example, $47 \%$ of people with abnormal $\mathrm{HbA}_{1 \mathrm{c}}$ had no other glycaemic abnormality). Lifestyle interventions were associated with a $36 \%$ ( $28 \%$ to $43 \%)$ reduction in relative risk of type 2 diabetes over six months to six years, attenuating to $20 \%$ ( $8 \%$ to $31 \%$ ) at follow-up in the period after the trails.

\section{CONCLUSIONS}

$\mathrm{HbA}_{1 c}$ is neither sensitive nor specific for detecting pre-diabetes; fasting glucose is specific but not sensitive. Interventions in people classified through screening as having pre-diabetes have some efficacy in preventing or delaying onset of type 2 diabetes in trial populations. As screening is inaccurate, many people will receives an incorrect diagnosis and be referred on for interventions while others will be falsely reassured and not offered the intervention. These findings suggest that "screen and treat" policies alone are unlikely to have substantial impact on the worsening epidemic of type 2 diabetes.

REGISTRATION

PROSPERO (No CRD42016042920).

\section{Introduction}

The prevalence of type 2 diabetes is rising globally; 422 million adults are living with diabetes, ${ }^{1}$ and the number expected to die from its complications is predicted to double between 2005 and 2030. ${ }^{1}$ In the United Kingdom about 3.2 million people have type 2 diabetes, and by 2025 it is predicted that this will increase to five million. ${ }^{2}$ This places considerable financial burden on the National Health Service (NHS). The healthcare cost of diabetes is estimated to be $€ 23.7 \mathrm{bn}$ ( $\$ 30.2 \mathrm{bn}, € 28.2 \mathrm{bn}$ ), a figure expected to rise to $€ 39.8$ bn by $2035-36$. $^{2}$ Preventing or delaying type 2 diabetes has become an international priority.

There are two approaches to prevention: screen and treat, in which a subpopulation is identified as "high risk" and offered individual intervention, and a population-wide approach, in which everyone is targeted via public health policies on environmental moderators ${ }^{3}$ (sociocultural influences, socioeconomic influences, transport, green spaces). Finland is taking a multi-level 


\section{Definition of terms}

\section{Oral glucose tolerance test}

- Two part blood test

- Part one: fasting plasma glucose (FPG). Blood test after overnight fast. If result is abnormal, diagnosis is impaired fasting glucose (IFG)

- Part two: 2 hour glucose tolerance test (2hrGT). Blood test two hours after ingestion of sugary drink. If result is abnormal, diagnosis is impaired glucose tolerance (IGT)

- Both tests can be performed independently of each other

$\mathrm{HbA}_{1 c}$

- Measurement of glycated haemoglobin, which reflects glucose concentration over two to three months. Accuracy impaired by haemoglobinopathies

\section{Pre-diabetes}

- Arbitrary category to encompass either IFG or IGT or abnormal $\mathrm{HbA}_{1 c}$

American Diabetes Association (ADA) diagnostic criteria

- Impaired fasting glucose 5.6-6.9 mmol/L

- Impaired glucose tolerance 7-11.1 mmol/L

- $\mathrm{HbA}_{1 \mathrm{c}}$ "at risk" range 39-47 mmol/mol (5.7-6.4\%)

WHO diagnostic criteria

- Impaired fasting glucose 6.0-6.9 mmol/L

- Impaired glucose tolerance 7-11.1 mmol/L

- $\mathrm{HbA}_{1 \mathrm{c}}$ "at risk" range $42-47 \mathrm{mmol} / \mathrm{mol}$ (6.0-6.4\%)

International Expert Committee (IEC) diagnostic criteria

- $\mathrm{HbA}_{1 \mathrm{c}}$ "at risk" range $42-47 \mathrm{mmol} / \mathrm{mol}$ (6.0-6.4\%)

approach to prevention by using both strategies. ${ }^{4}$ In contrast, the UK's National Diabetes Prevention Programme $^{56}$ follows Australia ${ }^{7}$ and the United States ${ }^{8}$ in placing the emphasis on a screen and treat approach.

There is international inconsistency on how to identify individuals at high risk of diabetes, to the extent that "a transatlantic trip may cure or cause diabetes simply as a result of small but important differences in diagnostic criteria." 9 In the US, the American Diabetes Association criteria recommend a diagnosis of pre-diabetes in people with a fasting plasma glucose concentration of 5.6-6.9 mmol/L or $\mathrm{HbA}_{1 \mathrm{c}}$ of $39-47 \mathrm{mmol} / \mathrm{mol}$ (5.7-6.4\%). WHO (World Health Organization) and the International Expert Committee recommend a fasting plasma glucose cut off of 6.0-6.9 mmol/L and $\mathrm{HbA}_{1 \mathrm{c}}$ of $42-47 \mathrm{mmol} / \mathrm{mol}(6.0-6.4 \%)$. The term pre-diabetes is used to encapsulate these ranges and implies that if individuals do not take action they will develop diabetes (though in reality this is not always the case). Since the recognition of pre-disease states (impaired glucose tolerance, impaired fasting glucose, and raised $\mathrm{HbA}_{1 \mathrm{c}}$ ), trials of lifestyle interventions have been associated with reduced or delayed onset of type 2 diabetes. ${ }^{10}$ Studies of screening and intervention programmes in real world settings, however, are sparse. ${ }^{11}$ Women with a history of gestational diabetes have a sevenfold risk of developing diabetes postpartum. ${ }^{12}$ These women might not be captured by the pre-diabetes umbrella term because many have normal glycaemic markers at the six week postpartum review and then fail to attend for annual review thereafter. ${ }^{13-17}$ Gestational diabetes is common in certain minority ethnic groups, ${ }^{18}$ and in deprived multi-ethnic areas a history of this condition could identify a considerable proportion of individuals who could benefit from preventive interventions.

We sought to inform national and local policymaking on prevention of type 2 diabetes by asking two questions. Which (if any) screening test should be used to identify people at risk of developing type 2 diabetes? What is the efficacy of preventive interventions (lifestyle and/or metformin) in those identified as high risk by screening?

\section{Methods}

\section{Search strategy}

We sought to identify all diagnostic accuracy and prevalence studies focusing on laboratory assessed $\mathrm{HbA}_{1 \mathrm{c}}$ and fasting plasma glucose (as recommended by the UK NICE (National Institute for Health and Care Excellence) ${ }^{19}$ ) as screening tools. Capillary glucose and $\mathrm{HbA}_{1 \mathrm{c}}$ point of care testing were excluded because of the lower reliability of these tests. For intervention studies we included trials whose participants were aged $\geq 18$ and had been identified as being in one of the "at risk" groups (impaired glucose tolerance, impaired fasting glucose, raised $\mathrm{HbA}_{1 \mathrm{c}}$, or a history of gestational diabetes). We studied two kinds of intervention: lifestyle programmes and metformin, compared with a control, in any setting, and that included weight change, change in glycaemic index, or incidence of diabetes as an outcome measure. Animal studies, molecular biology studies, studies related to children, surgical interventions, and interventions related to drugs other than metformin were excluded.

The study was undertaken from December 2014 to June 2016. It was commissioned by policymakers in a London borough with high prevalence of type 2 diabetes, and concerns about applicability to a real world setting helped shape the review questions. With assistance from a specialist librarian, three searches were undertaken: one for screening tests for pre-diabetes, another for intervention trials, and a third to identify studies relating to the prevention of type 2 diabetes in women with a history of gestational diabetes. Appendix 1 shows the full search strategy. Search terms (MESH and free text) included test, screening, pre-diabetes, impaired glucose tolerance, impaired fasting glucose, gestational diabetes, post-partum, ethnic groups, metformin, and lifestyle. EB manually extracted relevant titles from this dataset and reviewed abstracts to identify papers for full review. SR checked a random sample of 750 abstracts (20\%). Disagreements were resolved by discussion. Bilingual colleagues translated non-English papers and extracted data with guidance from the research team.

\section{Diagnostic accuracy meta-analysis}

Diagnostic accuracy studies were tabulated by index and reference test. Raw data for the meta-analysis on true positives, false positives, true negatives, and false negatives were extracted directly or calculated with the sensitivity and specificity information given in the paper. Additional data were extracted on population demographics, ethnicity, and diagnostic criteria used. We pooled studies in which $\mathrm{HbA}_{1 \mathrm{c}}$ was the index test and 
an oral glucose tolerance test was the reference standard. We presented these data separately for studies using the WHO criteria and studies not using these criteria (notably, some studies used the more stringent American Diabetes Association criteria to define pre-diabetes). We also pooled studies with the fasting plasma glucose as the index test and 2 hour glucose tolerance test as the reference test. Again we examined the data as a whole as well as separately by diagnostic criteria.

We undertook a bivariate diagnostic random effects meta-analysis ${ }^{20}$ to pool study level estimates of diagnostic accuracy using the reitsma function from the $\mathrm{R}^{21}$ package mada. ${ }^{22}$ In each case, we reported the pooled sensitivity, false positive rate, false negative rate, and 95\% confidence intervals. We plotted the bivariate summary receiver operating curve (sROC) over points representing study estimates of sensitivity and false positive rate, weighted by study size, and summarised the discriminative ability of each test using the area under the ROC (receiver operating characteristics) curve (AUROC) and the partial AUROC (which restricts the area to the observed false positive rates). Statistical heterogeneity was described with $\mathrm{I}^{2}$ statistic for bivariate meta-analysis. ${ }^{23}$

\section{Defining at risk population}

To compare differences in the at risk population identified by each test, we undertook a prevalence analysis. Using euler $A P E \mathrm{v} 3^{24}$ we analysed raw data from prevalence studies to assess the degree of overlap in the population identified as abnormal by each test. This analysis highlights the differing number of people eligi-

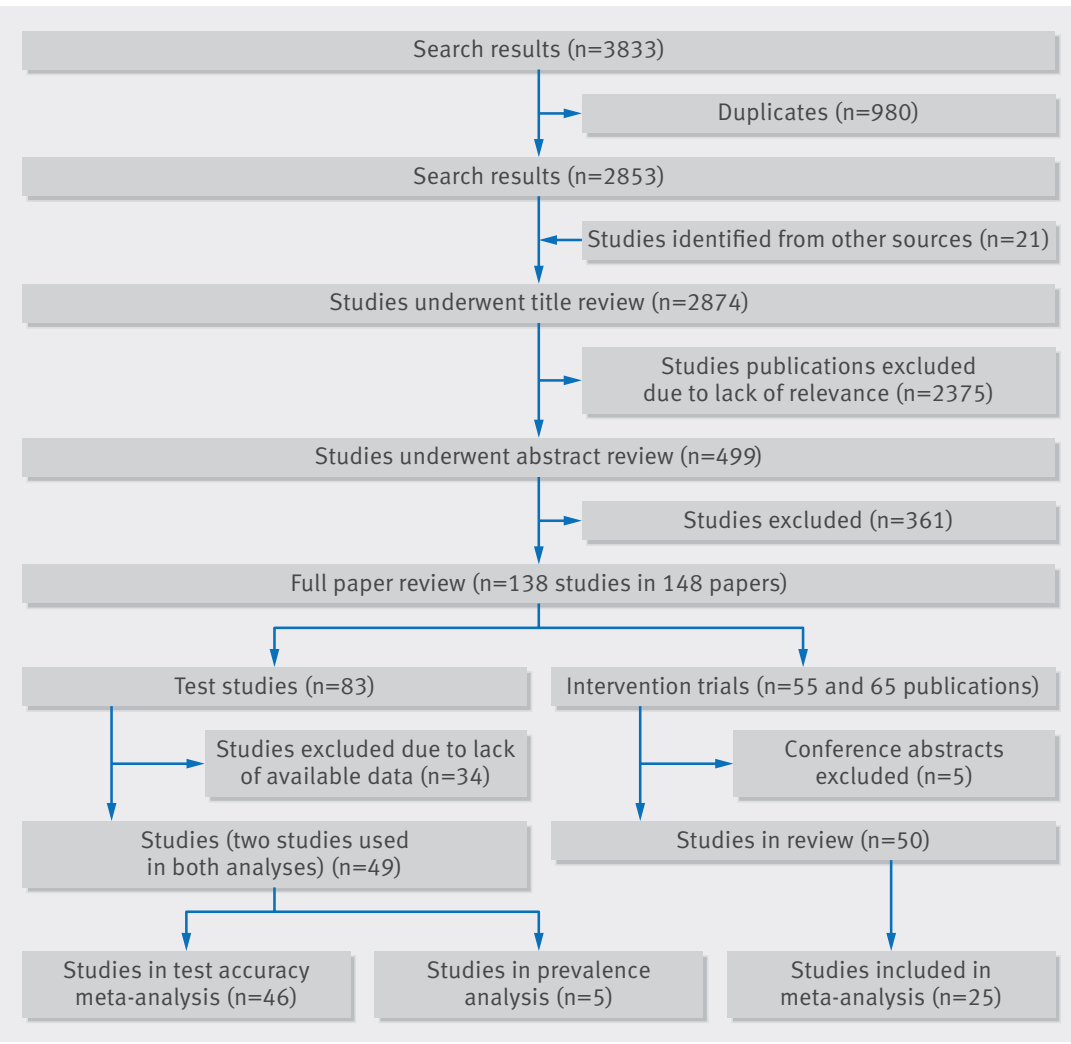

Fig 1 | Flow diagram of studies identified and included in review of efficacy and effectiveness of screen and treat policies in prevention of type 2 diabetes ble for interventions, depending on which test and criteria are used. We created Venn diagrams with the area of each ellipse proportional to the prevalence.

\section{Intervention trial review and meta-analysis}

Data extracted into Excel files from intervention trials included participants' demographics, type of intervention, intervention length, and primary and secondary outcomes. A second Excel sheet was used to tabulate results, including a clinically significant reduction in BMI $\left(1 \mathrm{~kg} / \mathrm{m}^{2}\right)$ or weight $(2 \mathrm{~kg})$, clinically significant improvement in glycaemic markers (normoglycaemia, or reduction in fasting plasma glucose by $0.5 \mathrm{mmol} / 1,2$ hour glucose tolerance by $>1 \mathrm{mmol} / \mathrm{L}, \mathrm{HbA}_{1 \mathrm{c}}$ to $<42$ $\mathrm{mmol} / \mathrm{mol}$ ), differences in incidence of diabetes between groups and whether this was significant. ${ }^{25} \mathrm{We}$ included in the meta-analysis any trial that collected data on incidence of diabetes. Data were extracted directly from the publications and processed with RevMan software. Because of the heterogeneity of the data we used a random effects model to create forest plots showing relative risk of developing type 2 diabetes after lifestyle interventions and metformin compared with usual care or no additional intervention.

\section{Assessment of study quality, applicability, and bias} To assess the quality and applicability of the test papers we used the validated QUADAS-2 tool, designed for the evaluation of diagnostic accuracy papers. ${ }^{26}$ After the refinement steps as recommended by the creators, two authors (EB and SR) piloted, adapted, and refined the tool before it was applied to all the papers used in the meta-analysis (see appendix 2). The limitations of the intervention trials were assessed with the Cochrane risk of bias tool ${ }^{27}$ and the CONSORT checklist. One author (RN) used the GRADE principles to assess the overall quality of the evidence at outcome level. ${ }^{27}$ An additional assessment was conducted to examine the extent to which participants were involved in the design of the intervention, if feedback was sought, if non-enrolment reasons were given, and if interventions could be adapted to meet the individual's needs.

\section{Patient involvement}

The review was conceptualised by a patient participation group led by the project lead (SV). Patients and clinicians raised questions on how best to identify those at risk of diabetes and explore how the Clinical Commissioning Group can support people in Newham to minimise their risk. In this way, patient and citizen involvement shaped the research question and methods of this review. The authors attended regular project meetings, reporting back the results of the review to the rest of the team, which included GP leads from the practices piloting interventions as well as the area lead for diabetes.

\section{Results}

\section{Search results}

Figure 1 shows the review flowchart. We fully reviewed 148 publications (83 relating to diagnostic accuracy testing and 65 relating to intervention trials). Data from 
46 papers were extracted and used to construct the diagnostic accuracy meta-analysis. We reviewed 50 unique intervention trials in full as well as publications related to these (protocol designs, subanalyses).

\section{Diagnostic accuracy of tests for pre-diabetes}

Table 1 lists the studies included in the diagnostic accuracy meta-analysis, with country of origin, population demographics, and QUADAS-2 assessment for bias and applicability. Figures 2 and 3 show the ROC curves constructed from data extracted from these trials. The pooled sensitivity of $\mathrm{HbA}_{1 \mathrm{c}}$ at identifying abnormalities as defined by the oral glucose tolerance test was 0.49 (95\% confidence interval 0.40 to 0.58 ); its specificity was 0.79 (0.73 to 0.84). Data were extracted from studies with both WHO and American Diabetes Association criteria, as well as studies that determined the optimal diagnostic cut offs using the optimal sensitivity and specificity assessed from their own populations. AUROC are used to estimate the overall diagnostic accuracy of a test with a value of 1 equating to the perfect test. The calculated AUROC of the $\mathrm{HbA}_{1 \mathrm{c}}$ was 0.71. A low sensitivity, however, leads to a high number of false negative results (that is, people incorrectly identified as not having diabetes). When this is taken into account (with the partial AUROC calculation) the accuracy reduces to 0.59. A subanalysis with the International Expert Committee/WHO criteria for $\mathrm{HbA}_{1 \mathrm{c}}$ did not alter the sensitivity of this test.

Analysis of studies that used the fasting plasma glucose as the index test found that this test had a sensitivity of 0.25 (95\% confidence interval 0.19 to 0.32 ) and specificity of 0.94 (0.92 to 0.96 ) at identifying impaired glucose tolerance. The analysis calculated an AUROC of 0.72, with a partial AUROC of 0.42. A subanalysis of studies using the criteria implemented in the UK did not change the results.

The main source of potential bias from these studies was selection bias. In many studies, the sampling strategy was unclear or participants self selected to attend for screening (for example, by answering an invitation or advertisement) rather than using a true population sample (random or consecutive). This was a particular concern in studies of follow-up after gestational diabetes, which usually defined their populations as women who had attended for the oral glucose tolerance tests, with no information on those who did not attend. Most diagnostic accuracy studies scored well on the QUADAS scale for applicability, indicating that the populations of patients were similar to those tested in primary care settings and the use of diagnostic tests and their interpretation was in keeping with our review question. These analyses showed a high level of heterogeneity, indicating that the test performs differently depending on population and setting. These are important considerations in the assessment of the diagnostic accuracy of the tests with specified populations. The results of the QUADAS tool were used to undertake a sensitivity analyses. Exclusion of studies at high risk of bias and outlying studies did not significantly alter the results (tables $A$ and $B$ in appendix 4).
Agreement between different diagnostic tests for pre-diabetes

Only five studies (table 2) gave a comparison of prevalence of pre-diabetes for all three tests $\left(\mathrm{HbA}_{1 \mathrm{c}}\right.$, fasting plasma glucose, 2 hour glucose tolerance test). With current International Expert Committee and WHO guidelines, $27 \%$ of the populations studied were identified as having "pre-diabetes" by one of the tests (of whom $48 \%$ had a raised $\mathrm{HbA}_{1 \mathrm{c}}$ alone, fig 4); if American Diabetes Association criteria for the HbA1c is applied to the same cohort, this figure was $49 \%$ (of whom $71 \%$ had a raised $\mathrm{HbA}_{1 \mathrm{c}}$ alone, see fig $\mathrm{F}$ in appendix 4). There was low agreement between the three tests on which individuals were classified as having pre-diabetes. Figure 4 illustrates this limited overlap. Substitution of the American Diabetes Association criteria for both the oral glucose tolerance test and $\mathrm{HbA}_{1 \mathrm{c}}$ increased the degree of overlap between the test results, but this doubled the estimated prevalence of pre-diabetes (fig 5).

\section{Interventions to prevent diabetes in screen detected pre-diabetes}

Fifty trials met our eligibility criteria ${ }^{1078-126}$ (tables A-D in appendix 3 summarise the methods and results of these studies). Only 25 of the trials (21 of lifestyle interventions alone, two of metformin alone, and two assessed both) had the necessary information available to be included in the meta-analysis. All trials were performed in adults identified as at risk of developing diabetes defined by the oral glucose tolerance test or had a history of gestational diabetes. There was heterogeneity in the number of participants in each trial (ranging from hundreds to thousands), length of interventions (four weeks to six years), intensity of intervention (frequency of contacts), and delivery method. Agreement between raters on data extraction was $100 \%$, with the exception of a single paper in which the authors did not distinguish between primary and secondary outcomes. Of 49 trials, 19 used the development of diabetes as a primary outcome measure. Some trials had begun with this outcome but during the trial substituted it for weight reduction and/or change in glycaemic markers because of low recruitment. ${ }^{78}$ Many studies showed differences in weight and change in glycaemic markers between groups that were statistically but not clinically significant. At the end of the intervention, 20 of the 49 trials showed a clinically significant reduction in weight between the groups, 15 showed a clinically significant improvement in glycaemic markers, and 23 showed some difference in favour of the intervention arm in the number of people developing diabetes, but this difference was significant only in seven of those trials (tables $\mathrm{C}$ and $\mathrm{D}$ in appendix 3 ).

Meta-analysis (fig 6) showed that lifestyle interventions reduced the relative risk of developing diabetes by $31 \%$ (95\% confidence interval $15 \%$ to $44 \%$ ) if the intervention lasted six months to two years. This translates to 69 (95\% confidence interval 56 to 85 ) out of 1000 people in the lifestyle intervention group developing diabetes compared with 100 out of 1000 without the intervention, or a number needed to treat (NNT) of 33 


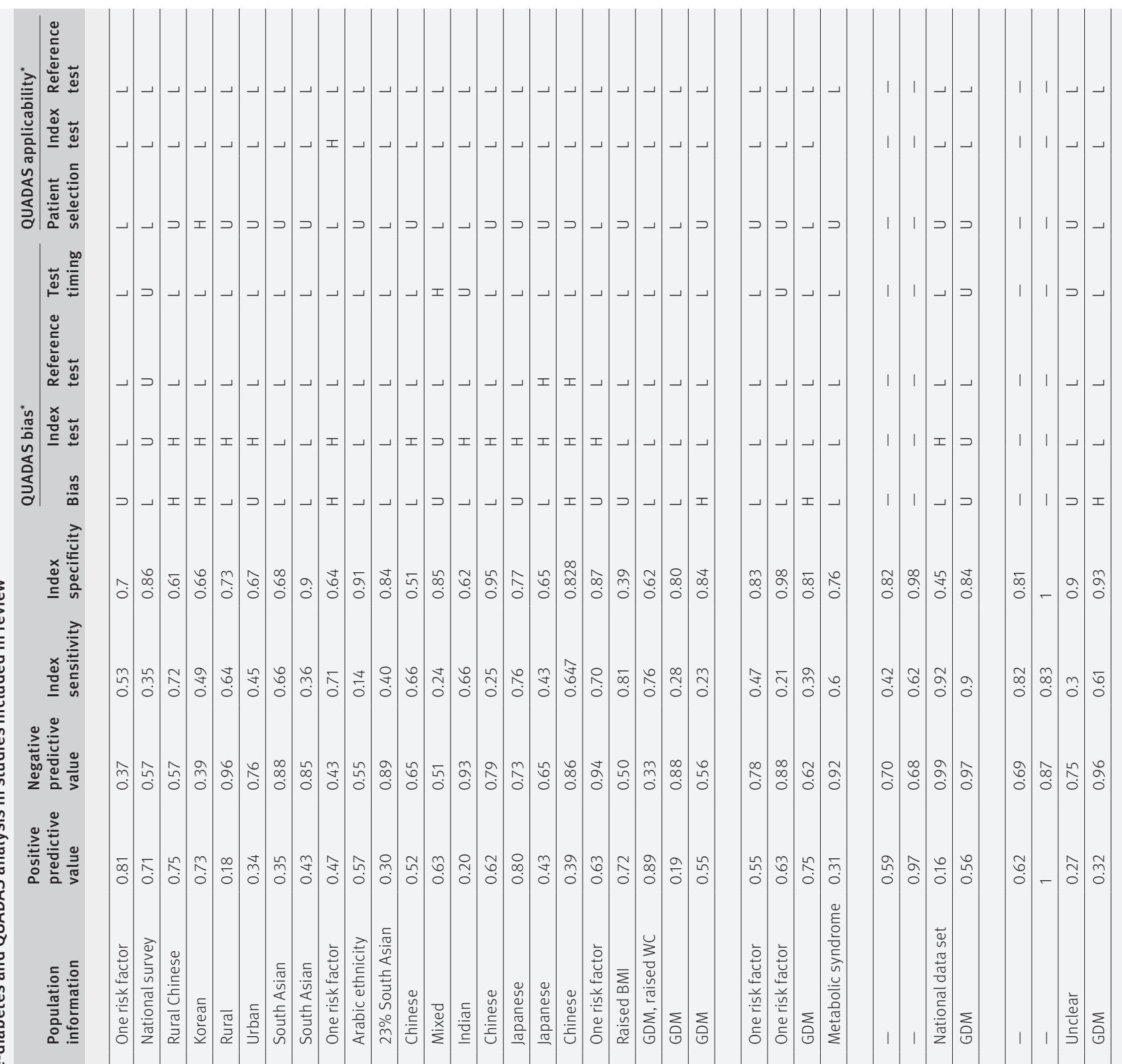

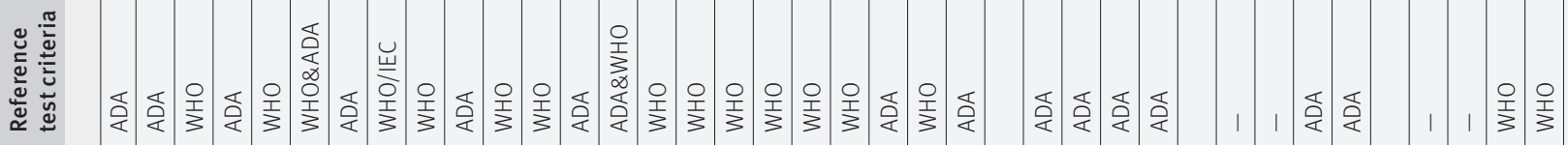

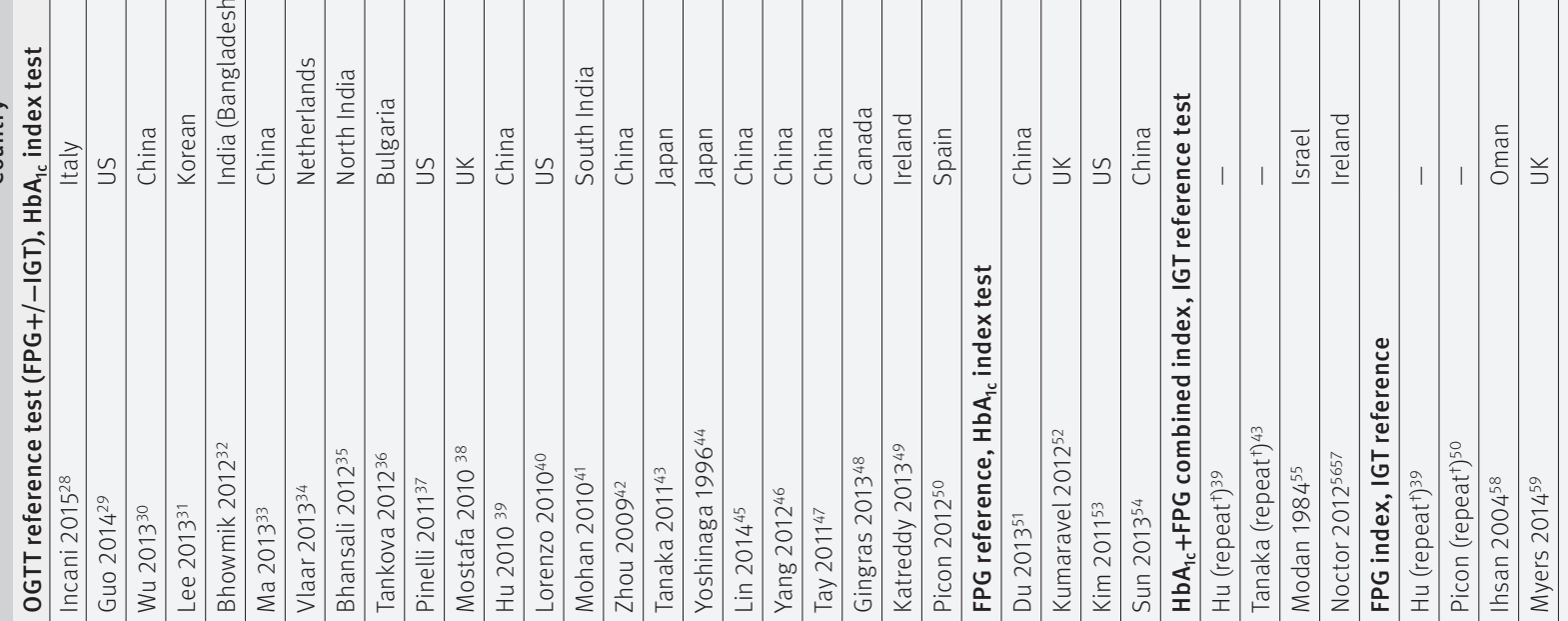




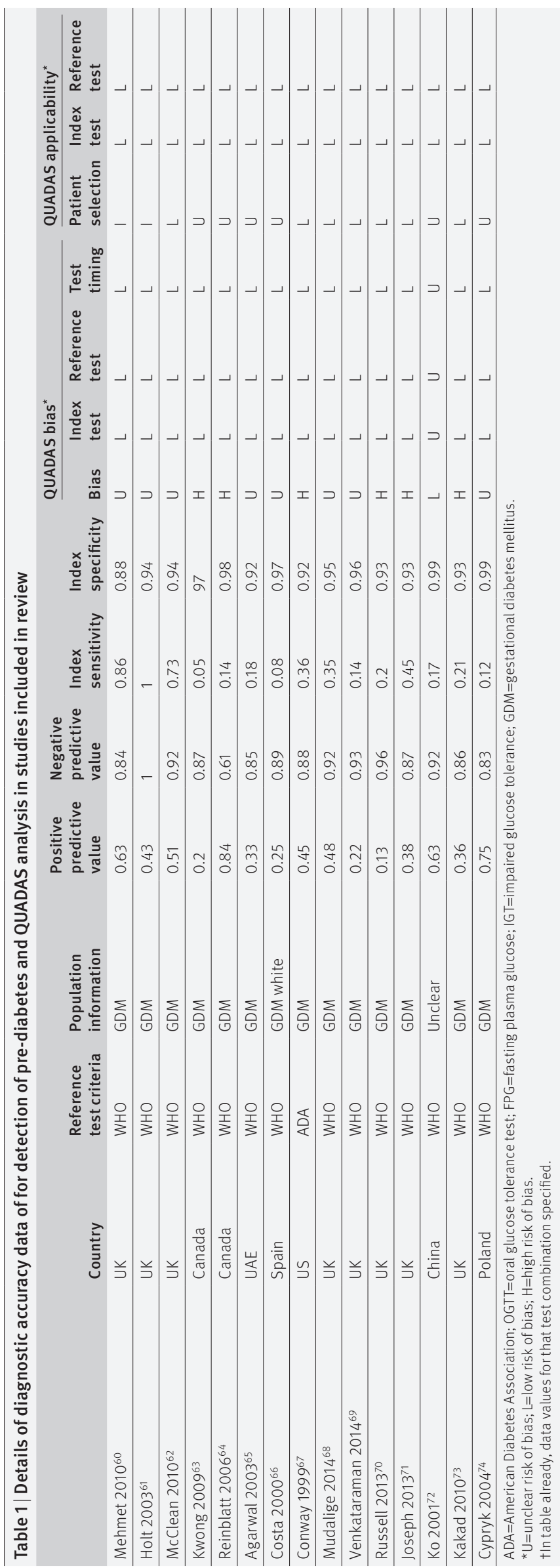

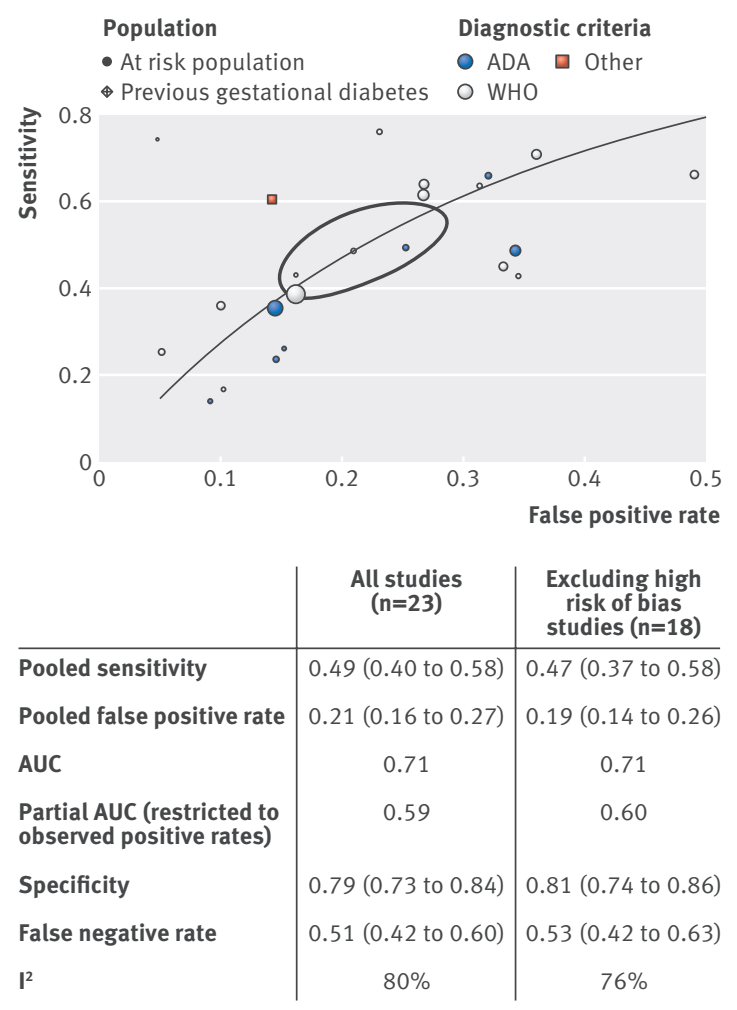

Fig $2 \mid$ ROC curve for studies using $\mathrm{HbA}_{1 \mathrm{c}}$ as index test and $\mathrm{OGTT}$ as reference standard. Area of ellipse is proportional to prevalence

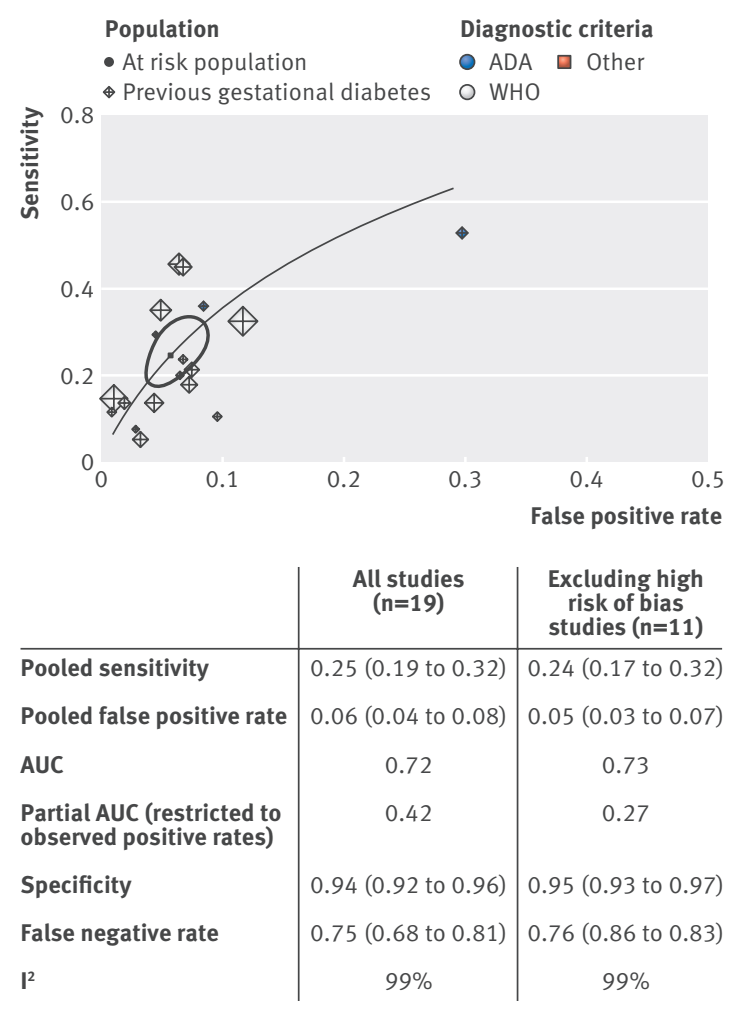

Fig $3 \mid$ ROC curve studies using FPG as index test and IGT as reference standard. Area of ellipse is proportional to prevalence 


\begin{tabular}{|c|c|c|c|c|c|c|c|}
\hline Author & Country & Population demographics & $\begin{array}{l}\text { Diagnostic } \\
\text { criteria for } \mathrm{HbA}_{1 \mathrm{c}}\end{array}$ & $\begin{array}{l}\text { Diagnostic } \\
\text { criteria for OGTT }\end{array}$ & $\begin{array}{l}\text { Total population } \\
\text { tested }\end{array}$ & $\begin{array}{l}\% \text { Tested population } \\
\text { "pre-diabetic" }\end{array}$ & $\begin{array}{l}\text { \% pre-diabetic } \\
\text { population with } \\
\text { abnormal } \mathrm{HbA}_{1 \mathrm{c}} \text { alone }\end{array}$ \\
\hline Incani28 & Italy & BMI >35 or DM risk factors & $\mathrm{ADA}$ & ADA & 1054 & 49 & 17 \\
\hline James $^{75}$ & USA & Mixed ethnicity. NHANES survey & ADA & ADA & 3627 & 37 & 8 \\
\hline Zhang $^{76}$ & China & Chinese. GHS population survey & ADA & ADA & 3590 & 66 & 29 \\
\hline Benaiges $^{77}$ & Spain & Mixed ethnicity. GDM & ADA & ADA & 141 & 42 & 25 \\
\hline Mostafa $^{38}$ & UK & WE and SA ethnicity & IEC & WHO & 8696 & 27 & 48 \\
\hline
\end{tabular}

$\mathrm{ADA}=$ American Diabetes Association; OGTT=oral glucose tolerance test; WE=west European; $\mathrm{SA}=$ South Asian.

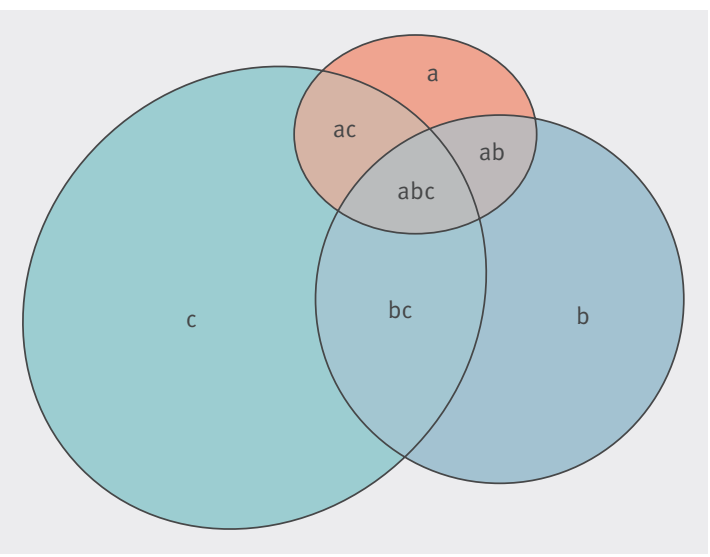

Fig 4 | Prevalence of pre-diabetes by diagnostic test with IEC and WHO criteria, showing overlap with all three tests. Prevalence of pre-diabetes was $27 \%$. Of those with abnormal results, $a=4.7 \%$ isolated IFG; $b=24.4 \%$ isolated IGT; $c=47.8 \%$ isolated $\mathrm{HbA}_{1 \mathrm{c}} ; \mathrm{ab}=\mathbf{2 . 9} \%$ IFG+IGT; $\mathrm{ac}=4.1 \%$ IFG $+\mathrm{HbA}_{1 c} ; \mathrm{bc}=12.2 \% \mathrm{IGT}+\mathrm{HBA}_{1 \mathrm{c}} ; \mathrm{abc}=3.9 \% \mathrm{IGT}+\mathrm{IFG}+\mathrm{HbA}_{1 \mathrm{c}}$; $\mathrm{d}$ (area outside ellipse) $=72 \%$ (normal result)

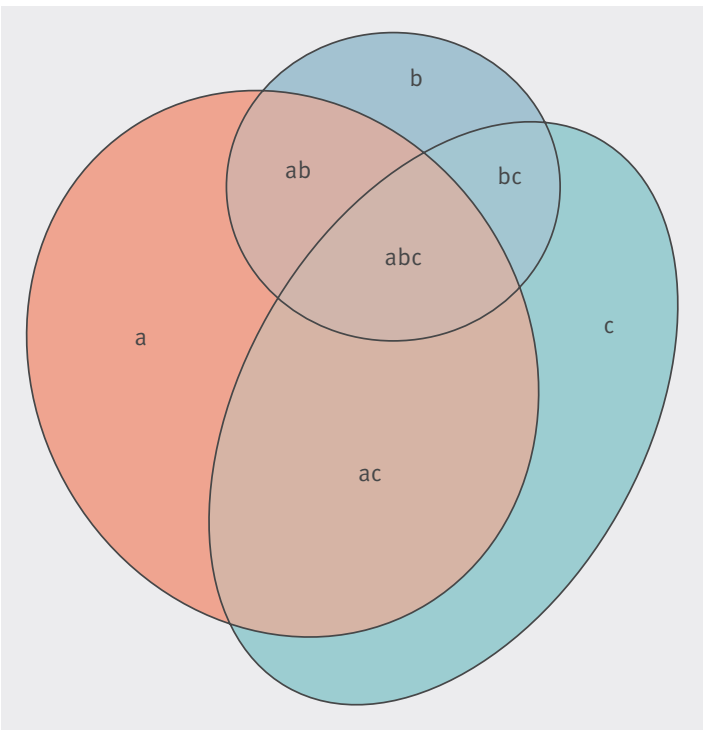

Fig 5 | Prevalence of pre-diabetes by diagnostic test with ADA criteria for all tests. Prevalence of pre-diabetes was $54 \%$. Of those with abnormal results, $a=25.4 \%$ isolated IFG; $b=6 \%$ isolated IGT; $c=22.4 \%$ isolated $\mathrm{HbA}_{1 c} ; a b=7.2 \%$ IFG+IGT; ac $=26.7 \%$ IFG $+\mathrm{HbA}_{1 c} ; \mathrm{bc}=3.6 \% \mathrm{IGT}+\mathrm{HBA}_{1 \mathrm{c}}$; $a b c=8.7 \%$ IGT + IFG $+H_{b A}$; $d$ (area outside ellipse) $=46 \%$ (normal result)
(95\% confidence interval 23 to 67). Lifestyle interventions lasting three to six years showed a $37 \%$ (28\% to $46 \%$ ) reduction in relative risk, equating to 151 (129 to 172) out of 1000 people in the lifestyle intervention group developing diabetes compared with 239 of 1000 in the control group (NNT 12, 10 to 15). The overall relative risk reduction of developing diabetes after lifestyle interventions was $36 \%$. Because of the small number of follow-up studies it is difficult to assess the reduction in risk of diabetes after the completion of lifestyle interventions. Our estimates show that relative risk reduction of developing diabetes fell to $20 \%$ ( $8 \%$ to $31 \%$ )) 8496110 127-129 in the period after the trial (fig 7).

Meta-analysis evaluating the impact of metformin (fig 8 ) showed a relative risk reduction of $26 \%$ (95\% confidence interval $16 \%$ to $35 \%$ ) while participants were taking this drug, translating to 218 (95\% confidence interval 192 to 248 ) out of 1000 developing diabetes while taking metformin compared with 295 of 1000 not receiving this drug (NNT 14 (95\% confidence interval 10 to 22)). The benefits of metformin were assessed at the end of the trial periods once the participants had been taking the drug for a prespecified length of time. There were no follow-up studies examining for persistence of benefit once metformin had been discontinued, but the US DPP study did show some improvements in reduction in incidence of diabetes with long term metformin use. ${ }^{130}$

The main sources of potential bias (as estimated by Cochrane risk of bias tool) were selection bias (lack of allocation concealment) and attrition bias (where authors used per protocol analysis instead of an intention to treat analysis to assess changes in outcome measures), potentially leading to overestimation of the benefits of the intervention. To provide the most comprehensive synthesis of relevant studies we did not pre-specify a minimum threshold of methodological quality for included studies. However, we performed a sensitivity analysis removing the studies at high risk of bias to test whether the exclusions of some trials changed the overall findings. Omission of these did not significantly change the overall results (for example, removal of the 2006 study by Ramachandran and colleagues ${ }^{106}$ did not significantly alter the relative risk reduction).

Using the GRADE approach, we assessed the evidence to be of moderate quality for progression to type 2 diabetes with metformin versus control, low quality for lifestyle interventions of one to two years and three to six years' duration versus control, and very low qual- 


\section{Study}

Intervention 6 months-2 years

Yates 2009

Katula 2013

Ramachandran 2013

Perez-Ferre

Oldroyd 2006

Xu D.F 2013

Subtotal $(95 \% \mathrm{Cl})$
Ferrara 2016

No of events/total Experiment Control$$
1 / 64
$$

$13 / 151$

$50 / 271$

$11 / 130$

$37 / 1087$

$7 / 39$

$7 / 46$

$126 / 1788 \quad 185 / 1854$

Test for heterogeneity: $\tau^{2}=0.00, \chi^{2}=4.62, d f=6, P=0.59, I^{2}=0 \%$

Test for overall effect: $z=3.48, P<0.001$

Intervention 3-6 years

Kosaka 2005

Eriksson 1991

Tuomilehto 2001

US DPP 2002

Sakane 2011

Penn 2009

Roumen 2008

China Da Qinq 1997

Ramachandran 2006

Bhopal 2014

Saito 2011

Shek 2014

Davies 2016

Subtotal $(95 \% \mathrm{Cl})$

$\begin{array}{cc}3 / 102 & 32 / 356 \\ 17 / 181 & 16 / 79 \\ 27 / 265 & 59 / 257 \\ 155 / 1079 & 313 / 1082 \\ 9 / 152 & 18 / 152\end{array}$

$7 / 51$

$11 / 74$

$188 / 438$

$52 / 133$

$12 / 85$

$35 / 311$

$33 / 225$

$64 / 447$

$613 / 3543$

$19 / 73$

$90 / 138$

$75 / 136$

$17 / 86$

$51 / 330$

$43 / 225$

$67 / 443$

Test for heterogeneity: $\tau^{2}=0.03, \chi^{2}=21.68, \mathrm{df}=12, \mathrm{P}=0.04, \mathrm{I}^{2}=45$ Test for overall effect: $z=6.32, P<0.001$

Total $(95 \% \mathrm{Cl})$

$739 / 5331998 / 5262$

Test for heterogeneity: $\tau^{2}=0.02, \chi^{2}=27.01, \mathrm{df}=19, \mathrm{P}=0.10, \mathrm{I}^{2}=30 \%$

Test for overall effect: $z=7.56, P<0.001$

Test for subgroup differences: $\chi^{2}=0.52, \mathrm{df}=1, \mathrm{P}=0.47, \mathrm{I}^{2}=0 \%$

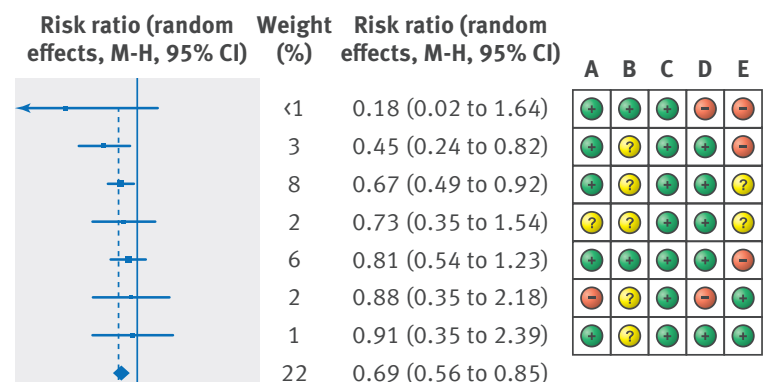

$0.33(0.10$ to 1.05$)$ 0.46 (0.25 to 0.87$)$ 0.44 (0.29 to 0.68 )

0.50 (0.42 to 0.59)

0.50 (0.23 to 1.08$)$

0.54 (0.23 to 1.24$)$

0.57 (0.29 to 1.11$)$

0.66 (0.56 to 0.77 )

0.71 (0.55 to 0.92)

0.71 ( 0.36 to 1.40$)$

0.73 (0.49 to 1.09 )

$0.77(0.51$ to 1.16$)$

0.95 (0.69 to 1.30$)$

0.63 (0.54 to 0.72 )
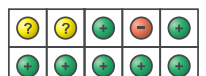

$+(?) \odot \odot$

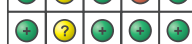

(?) $\odot \odot \odot \odot$

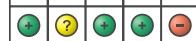

(?) (?) $\odot \odot$

๑) $\odot \odot \odot ~$
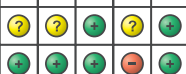

$+\odot$

$\odot$ (๑)

$\odot \odot \odot$ (?)

\footnotetext{
(n)
}

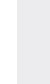




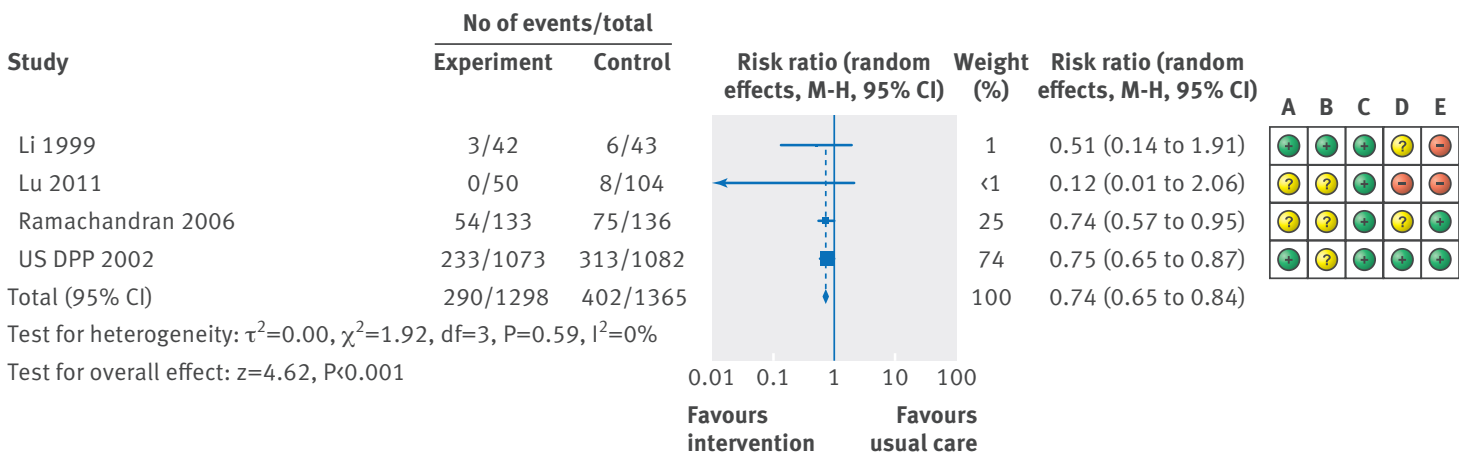

Fig 8 Relative reduction in risk of diabetes at end of metformin trial. A=random sequence generation (selection bias); $B=$ allocation concealment (selection bias); $C=$ blinding of outcome assessment (detection bias); $D=$ incomplete outcome data (attrition bias); $\mathrm{E}=$ selective reporting (reporting bias)

risk (oral glucose tolerance test) is not widely used in practice. A further downgrade was because of the statistical heterogeneity in two out of the four outcomes (lifestyle interventions with a three to six year follow $=$ up $\left(\mathrm{I}^{2}=45 \%\right.$; downgraded once $)$ and follow-up after intervention ( $\mathrm{I}^{2}=82 \%$; downgraded twice)). This high degree of heterogeneity is probably because of differences in sample size and length and intensity of interventions included in this analysis, but the small number of trials contributing to the follow-up analysis after intervention limited our ability to explore this using subgroup analysis. Seven papers ${ }^{10} 95101105106116126$ described at least one element of patient and participant involvement. Most interventions were inflexible, with a one-size-fits-all approach.

\section{Gestational diabetes}

Nine trials assessed lifestyle interventions in women with a history of gestational diabetes (see tables B and D, appendix 3). These focused on diet, exercise, and increased uptake of breast feeding. None showed a significant reduction in incidence of diabetes between the intervention and control groups. Attrition rates were high in these trials. Only three trials had sufficient data to be included in the meta-analysis.

\section{Withdrawal and attrition rates}

Sixteen studies had the necessary data available to assess withdrawal and attrition rates. ${ }^{1078} 81929697101103$ 105-107 109110116118126 Of the pre-diabetic population identified, only $27 \%$ went on to complete the trial (the rest were either not eligible, declined to participate, or withdrew from the intervention (fig 9)). Therefore, relative risk reductions calculated from intervention trials reflect risk improvements seen in a limited proportion of the total pre-diabetic population.

\section{Discussion}

\section{Principal findings}

This systematic review, commissioned by local policymakers who wanted to identify an effective "screen and treat" strategy for prevention of type 2 diabetes in an area of high prevalence, included 99 studies and produced four main findings. Firstly, the diagnostic accuracy of tests used to detect pre-diabetes in screening

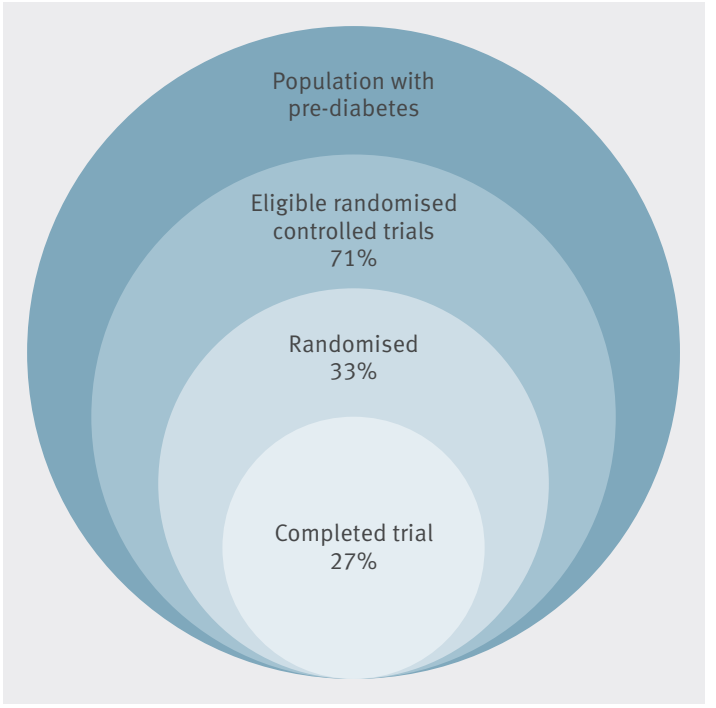

Fig 9 Attrition rate from at risk population to trial completion. Data from research studies suggest high attrition and withdrawal rates in screen and treat programmes. Overall, only $27 \%$ of people in eligible pre-diabetic population completed trial of preventive intervention

programmes is low. The most commonly used test $\left(\mathrm{HbA}_{1 \mathrm{c}}\right)$ is neither sensitive nor specific; the fasting glucose test is specific but not sensitive. Low sensitivity results in a high number of people with false negative results, resulting in a large number being falsely reassured. Secondly, the diagnostic tests identify different pre-diabetic population groups with limited overlap. If the American Diabetes Association criteria are used instead of WHO ones, the prevalence of those with a diagnosis of pre-diabetes doubles. Thirdly, both individually targeted lifestyle interventions and metformin have some efficacy in preventing or delaying the onset of type 2 diabetes, though the protective effect of the former is greatest in longer interventions (three to six years) and attenuates with time from intervention. We have only moderate to very low confidence in these estimates, however, because study quality was often low. Finally, in women with a history of gestational diabetes, the evidence base for lifestyle interventions in preventing progression to type 2 diabetes is currently weak. 
Most intervention trials included in this study used the oral glucose tolerance test to identify their study population. In practice, however, this test is not widely used. It is time consuming, requires fasting and ingestion of a sugary drink (which many people find unpleasant), and, because of variability within an individual, needs to be done twice. $\mathrm{HbA}_{1 \mathrm{c}}$ is estimated on a single non-fasting blood test but varies by ethnicity, leading to overestimation and underestimation of the result, ${ }^{131-133}$ and could be inaccurate in the presence of haemoglobinopathy. The fasting plasma glucose test is a single blood test but requires the person to have fasted for several hours so is impractical for mass screening.

Accuracy of tests depends on cut-off points. By using the International Expert Committee and WHO criteria for defining pre-diabetes, $\mathrm{HbA}_{1 \mathrm{c}}$ correctly identifies only half the individuals with an abnormal result on an oral glucose tolerance test but also assigns the label of pre-diabetes to large numbers of individuals with a normal test result. Different diagnostic criteria result in a different estimate of the prevalence of pre-diabetes; this will have implications for which (and how many) individuals are eligible for lifestyle interventions. Furthermore, people identified with $\mathrm{HbA}_{1 \mathrm{c}}$ might not have the same glycaemic abnormality as those entered into trials on the basis of an oral glucose tolerance test and might respond differently to interventions.

Systematic reviews assessing progression from at risk states to diabetes have shown that those at most risk of developing diabetes had both impaired fasting glucose and impaired glucose tolerance; $\mathrm{HbA}_{1 \mathrm{c}}$ showed a lower progression rate, similar to impaired fasting glucose alone. ${ }^{134-136}$ Those with a history of gestational diabetes have the highest rates of progression to diabetes, with a sevenfold increased risk after the first diagnosis ${ }^{12}$ and a $70 \%$ cumulative incidence at 10 years. ${ }^{137}$

Of the 50 intervention trials included in this review, 34 used surrogate endpoints (most commonly, weight loss) as their primary outcome. While most found significant changes in these endpoints, authors rarely commented critically on the sustainability or clinical importance of these. Weight reduction has been shown to correlate poorly with the reduction in incidence of diabetes in some populations. ${ }^{106}$ The trials in our sample that did show a significant reduction in the definitive endpoint of incidence of diabetes lasted between three and six years and were intensive in nature with individuals closely monitored.

While reduced incidence of diabetes seems to be possible if the interventions are intensive, the relative risk reductions seen in trials apply only to those who enrol and adhere to the intervention. Given the number of people who will not meet eligibility criteria or who decline or do not complete the intervention (fig 9), there is no scientific basis for extrapolating percentage risk reductions seen in trials to an equivalent reduction in incidence of diabetes across an entire community. Poor enrolment and completion of lifestyle interventions will limit the impact national prevention programmes will have on the overall burden of disease.

\section{Comparison with other systematic reviews}

This systematic review is the first to combine the analysis of diagnostic accuracy with efficacy of interventions to give an overall estimate of how screen and treat policies could play out in populations, focusing on the endpoint of progression to type 2 diabetes. Edwardson and colleagues reviewed the effectiveness of risk scores and lifestyle interventions but did not assess their accuracy and the implications of their use. ${ }^{138}$ Other systematic reviewers performed a more in-depth analysis of improvement in surrogate endpoints such as weight loss and improvements in glycaemic markers. ${ }^{11}{ }^{139-142}$ A review carried out by the Institute for Clinical and Economic Review, however, raised concerns regarding the clinical importance and sustainability of improvements of these surrogate markers. ${ }^{143}$

Other systematic reviews have found similar relative risk reductions in incidence of diabetes with lifestyle interventions and metformin in study populations. ${ }^{142}$ Previous meta-analyses showed a higher relative risk reduction when they included only the most tightly controlled trials with stringent population enrolment criteria. ${ }^{144} 145$ In contrast, Public Health England's meta-analysis of translational studies identified a lower relative risk reduction because of the inclusion of pragmatic trials and observational studies ${ }^{146}$ and showed high levels of statistical heterogeneity between primary studies. One systematic review assessed UK based community and national interventions whose participants were the most deprived, vulnerable, and socially excluded (groups often omitted from clinical trials). ${ }^{147}$ They found that the effects of the interventions were small in these groups, with no evidence of long term reduction in incidence of diabetes.

Labelling people as having "pre-diabetes" has important personal implications (medicalisation, intrusive testing, and stigma) for people who might never go on to develop diabetes. Other scholars have voiced similar concerns to those raised in this systematic review with regards to the danger of inaccurate classification and/or overdiagnosis with tests for pre-diabetes, ${ }^{148}$ effectiveness of lifestyle interventions in the real world, ${ }^{149}$ and the limited impact of screen and treat policies in the absence of a complementary population based approach. ${ }^{150}$

Whether these interventions reduce longer term cardiovascular morbidity and mortality remains unclear. A meta-analysis and systematic review undertaken by Hopper and colleagues ${ }^{151}$ agreed with our findings that lifestyle interventions can reduce the relative risk of developing diabetes. While these interventions did result in a reduction in incidence of cardiovascular events, this did not translate into a significant reduction in all cause or cardiovascular mortality. Long term follow-up studies undertaken by the Chinese Da Qinq study and the Finnish Diabetes Prevention Study found that there was no significant difference between intervention and control groups in first cardiovascular events $^{127}$ or cardiovascular morbidity, ${ }^{152}$ though the study was not powered to detect such a difference. 
Meaning and implications for policy makers, clinicians, and academics

This review was requested by a local clinical commissioning group in an inner London borough where the local diabetes prevention programme has largely consisted of a community prescription initiative offered to people classified as having pre-diabetes with a BMI of 27 or above, a history of gestational diabetes, or a QRISK $>20 \%$. Intensive interventions lasting years, such as those included in this systematic review, are not an option given its limited budget.

Our findings indicate that in settings such as this, screen and treat policies for pre-diabetes will benefit individuals who are "true positives" and have sufficient personal, family, and community resources to enable them to attend and comply with preventive interventions. Incentivised diabetes prevention programmes will also pick up people with undiagnosed diabetes (an estimated $2-10 \%$ of those screened ${ }^{3878} 81116126$ ), who can be offered timely management. A considerable proportion of people at high risk of developing type 2 diabetes, however, will go on to develop the condition despite such programmes. These include people who test "false negative" and those who, despite testing positive and being offered a lifestyle intervention, lack the personal resources and social connections to support and sustain lifestyle change.

Because of the low accuracy of screening tests and the limited reach of intervention programmes, policymakers might want to consider supplementing screen and treat policies with population based approaches aimed at entire communities. WHO, for example, proposes "multisectoral action that simultaneously addresses different sectors that contribute to the production, distribution and marketing of food, while concurrently shaping an environment that facilitates and promotes adequate levels of physical activity." 153

\section{Strengths and limitations}

This is the first systematic review to assess both the diagnostic accuracy of screening tests for pre-diabetes and the efficacy of interventions in those classified through screening as having pre-diabetes. Furthermore, it is a comprehensive review synthesising a large volume of international literature, including translations from languages other than English. It was inspired by a question by front line policymakers and focused on producing a practical answer to that question. As such, and unlike much secondary and primary research, it fulfils the important criterion of "usefulness."154

The main limitation of the review was the number of exclusions because of incomplete data available in published studies. Despite efforts to contact authors, we were unable to obtain the data needed to contribute to the meta-analysis in 18 potentially eligible papers. In the prevalence analysis, only five out of 28 papers compared all three diagnostic tests, so these findings should be interpreted with caution. A high proportion of studies that assessed the diagnostic accuracy of fasting plasma glucose did so in participants with a history of gestational diabetes-a bias that could influence the generalisability of this analysis.

Only half of the intervention studies were included in the meta-analysis because the lengths of the trial or intervention were too short to be able to capture incidence of diabetes. Additionally, the analysis of the reduction in the risk of diabetes at various follow-up periods was limited because of the small number of primary studies that performed follow-up analyses. We recommend that primary studies of diabetes prevention programmes should be resourced to undertake long term follow-up to assess for sustained benefits including incidence of diabetes, cardiovascular morbidity, and mortality.

Intervention studies that used risk scores to identify their population instead of blood tests do exist ${ }^{155}$ but were outside the scope of this systematic review. Further synthesis of interventions using wider population eligibility criteria could provide additional insights into the benefits of these.

\section{Future work}

On the basis of the findings of this review, we suggest three avenues for further research. The first is pragmatic real world effectiveness and cost effectiveness studies of interventions for pre-diabetes that have already been shown to be efficacious in trials. ${ }^{149} 156$ Studies of the translational gap between evidence from randomised trials and real world uptake and impact is always important ${ }^{157}$ but particularly so when the "real world" seems unlikely to be able to replicate the conditions (for example, health literacy, language fluency, and comorbidities of target population; intensity and duration of intervention; completeness of follow-up) that characterised the trials with the most positive results. ${ }^{149158}$ These real world studies should deal with the impact on behaviour of individuals who test positive for pre-diabetes (only a third of whom would be predicted to engage with interventions; fig 9) and the costs (to both participants and the health service). More specifically, effectiveness and cost effectiveness studies should explore the implications of screen and treat programmes for both commissioners and providersincluding the opportunity costs of spending a limited budget on a programme for which a variable proportion of the pre-diabetic population would be eligible for and engage with depending on locality.

The second avenue for further research is the evaluation of population level and/or health system interventions. Individual lifestyle choices are constructed by sociocultural, political, and economic influences, which might be more effectively deal with by using population-wide strategies such as protection of green spaces, increased walkability of the environment, affordable leisure activities, improved food labelling, independent regulation of food nutritional standards, regulation on food advertising, affordable fruit and vegetables, and school based programmes. Such systematic structural approaches dealing with "upstream" influences on the pathogenesis of diabetes require well supported public health teams working alongside local 
governments to improve the health of communities and could be vital components of a multifaceted long term primary prevention strategy. ${ }^{159}$

Currently, only a tiny fraction of the literature on diabetes prevention is informed by an appreciation of the social complexity underlying pathogenesis of diabetes. ${ }^{160-162}$ The 2014 Foresight Report on Obesity was a model of good practice in teasing out the complex interactions between genetic, physiological, psychological, sociocultural, economic, and political determinants of obesity; it provided a strong and consistent message that short term "behaviour change" interventions were unlikely to succeed in isolation. ${ }^{163} \mathrm{~A}$ comparable initiative for type 2 diabetes could add richness to our current understanding of the condition and help to inform the design of evidence based strategies aimed at influencing its "upstream" determinants.

\section{Conclusion}

As the prevalence of type 2 diabetes rises inexorably in high, middle, and low income countries alike, controversy continues to surround the questions of who is "at risk" and what preventive interventions to offer them. A screen and treat policy will be effective only if a test exists that correctly identifies those at high risk (sensitivity) while also excluding those at low risk (specificity); and an intervention exists that is acceptable to, and also efficacious in, those at high risk. This review has shown that of the two screening tests for pre-diabetes that are available and acceptable to patients and clinicians, fasting glucose is specific but not sensitive and $\mathrm{HbA}_{1 \mathrm{c}}$ is neither sensitive nor specific. Trial evidence suggests that lifestyle interventions have a potential role in reducing individual progression to diabetes and could benefit those high risk individuals who have the motivation and social support to achieve sustained lifestyle change. Given that this is likely to be a limited proportion of the population identified with pre-diabetes, however, substantial research resources should be directed at the evaluation of upstream interventions aimed at the entire population.

Contributors: EB conceptualised the review, assisted with developing the search strategy and ran the search, scanned all titles and abstracts, extracted quantitative data on all the papers, checked citations, performed the prevalence analysis, performed the meta-analysis of the intervention studies, undertook the QUADAS, risk of bias, and CONSORT assessment, and co-wrote and revised drafts of the paper. SR conceptualised the review, independently reviewed the data extraction process from the search results and methods from the intervention papers, adapted the QUADAS and risk of bias tool verifying the methods, and checked a sample of this assessment. J0 advised on the analysis of the quantitative data and carried out the diagnostic accuracy bivariate meta-analysis. RN advised on the quality assessment of the literature and undertook the GRADE assessment. $\mathrm{RN}$ also reviewed drafts of the paper and assisted with graphically representing the risk of bias tool using RevMan. SV conceptualised the study, framed the question, and manages the project steering group. TG is the academic supervisor for the project, conceptualised the study, advised on systematic review methods, and co-wrote and revised drafts of the paper. TG is guarantor. All authors, external and internal, had full access to all of the data (including statistical reports and tables) in the study and can take responsibility for the integrity of the data and the accuracy of the data analysis.

Funding: This study was funded by grants from the Newham Clinical Commissioning Group and University College London Partners, a
National Institute for Health Research fellowship for EB, National Institute for Health Research senior investigator award for TG, and by internal funding for staff time from the Nuffield Department of Primary Care Health Sciences, University of Oxford. The funders had no input into the selection or analysis of data or the content of the final manuscript.

Competing interests: All authors have completed the ICMJE uniform disclosure form at www.icmje.org/coi_disclosure.pdf (available on request from the corresponding author) and declare: no support from any organisation for the submitted work; no financial relationships with any organisations that might have an interest in the submitted work in the previous three years; and no other relationships or activities that could appear to have influenced the submitted work.

Ethical approval: Not required.

Data sharing: No additional data available.

Transparency: The lead author (the manuscript's guarantor) affirms that the manuscript is an honest, accurate, and transparent account of the study being reported; that no important aspects of the study have been omitted; and that any discrepancies from the study as planned have been explained.

We thank Helen Elwell, BMA librarian, for help with the literature search, and Geoffrey Wong, Marija Cvetkovic, and Zoya Georgieva for help with translation of non-English papers. Thanks to Newham Clinical Commissioning Group and University College Partners for their support of this project.

1 World Health Organisation. Diabetes Fact Sheet No 312. http:// www.who.int/mediacentre/factsheets/fs312/en/. WHO; 2016.

2 Diabetes UK. Diabetes: Facts and Stats. https://www.diabetes.org.uk/ Documents/About\%20Us/Statistics/Diabetes-key-stats-guidelinesApril2014.pdf. 2015

3 Swinburn BA, Sacks G, Hall KD, et al. The global obesity pandemic: shaped by global drivers and local environments. Lancet 2011;378:804-14. doi:10.1016/S0140-6736(11)60813-1.

4 Saaristo T, Moilanen L, Korpi-Hyövälti E, et al. Lifestyle intervention for prevention of type 2 diabetes in primary health care: one-year follow-up of the Finnish National Diabetes Prevention Program (FIN-D2D). Diabetes Care 2010;33:2146-51. doi:10.2337/dc10-0410.

5 England NHS. NHS Five Year Forward View. October 2014. https:// www.england.nhs.uk/wp-content/uploads/2014/10/5yfv-web.pdf on 21.7.16. London 2014

6 England NHS. NHS Diabetes Prevention Programme (NHS DPP). https://www.england.nhs.uk/ourwork/qual-clin-lead/diabetesprevention/. London 2015.

7 Diabetes Australia. Information on prevention programmes. https:// www.diabetesaustralia.com.au/prevention.2016.

8 Center for Disease Control and Prevention. National Diabetes Prevention Programme. http://www.cdc.gov/diabetes/prevention/ index.html 2016.

9 Borch-Johnsen K, Colagiuri S. Diagnosing diabetes--time for a change?Diabetologia 2009;52:2247-50. doi:10.1007/ s00125-009-1526-1.

10 Knowler WC, Barrett-Connor E, Fowler SE, et al. Diabetes Prevention Program Research Group. Reduction in the incidence of type 2 diabetes with lifestyle intervention or metformin. N Engl I Med 2002:346:393-403. doi:10.1056/NEJMoa012512.

11 Cardona-Morrell M, Rychetnik L, Morrell SL, Espinel PT, Bauman A. Reduction of diabetes risk in routine clinical practice: are physical activity and nutrition interventions feasible and are the outcomes from reference trials replicable? A systematic review and metaanalysis. BMC Public Health 2010;10:653. doi:10.1186/1471-2458-10-653.

12 Bellamy L, Casas JP, Hingorani AD, Williams D. Type 2 diabetes mellitus after gestational diabetes: a systematic review and meta-analysis. Lancet 2009;373:1773-9. doi:10.1016/S0140-6736(09)60731-5.

13 Lie ML, Hayes L, Lewis-Barned NJ, May C, White M, Bell R. Preventing type 2 diabetes after gestational diabetes: women's experiences and implications for diabetes prevention interventions. Diabet Med 2013:30:986-93. doi:10.1111/dme.12206

14 Paez KA, Eggleston EM, Griffey SI, et al. Understanding why some women with a history of gestational diabetes do not get tested for diabetes. Womens Health Issues 2014;24:e373-9. doi:10.1016/j. whi.2014.04.008.

15 Sterne V, Logan T, Palmer MA. Factors affecting attendance at postpartum diabetes screening in women with gestational diabetes mellitus. PractDiabetes Int 2011:28:64-8. doi:10.1002/pdi.1559.

16 Lega IC, McLaughlin H, Coroneos M, Handley-Derry F, Donovan N, Lipscombe LL. A physician reminder to improve postpartum diabetes screening in women with gestational diabetes mellitus. Diabetes Res Clin Pract 2012;95:352-7. doi:10.1016/j.diabres.2011.10.023.

17 Nicklas JM, Zera CA, Seely EW, Abdul-Rahim ZS, Rudloff ND, Levkoff SE. Identifying postpartum intervention approaches to prevent type 2 diabetes in women with a history of gestational diabetes. BMC Pregnancy Childbirth 2011;11:23. doi:10.1186/1471-2393-11-23. 
18 Greenhalgh T, Clinch M, Afsar N, et al. Socio-cultural influences on the behaviour of South Asian women with diabetes in pregnancy: qualitative study using a multi-level theoretical approach. BMC Med 2015;13:120. doi:10.1186/s12916-015-0360-1.

19 National Institute for Health and Care Excellence. Type 2 diabetes: prevention in people at high risk. NICE Guideline PH 38. https://www. nice.org.uk/guidance/ph38. 2012

20 Reitsma JB, Glas AS, Rutjes AW, Scholten RJ, Bossuyt PM, Zwinderman $\mathrm{AH}$. Bivariate analysis of sensitivity and specificity produces informative summary measures in diagnostic reviews. J Clin Epidemiol 2005;58:982-90. doi:10.1016/j.jclinepi.2005.02.022.

21 R Core Team. R: A language and environment for statistical computing [Internet]. https://www.r-project.org/.Vienna, Austria2016.

22 Doebler P. MADA: Meta-analysis of diagnostic accuracy. https:// cran.r-project.org/package=mada. 2016.

23 Zhou Y, Dendukuri N. Statistics for quantifying heterogeneity in univariate and bivariate meta-analyses of binary data: the case of meta-analyses of diagnostic accuracy. Stat Med 2014;33:2701-17. doi:10.1002/sim.6115

24 Micallef L, Rodgers P. eulerAPE: drawing area-proportional 3-Venn diagrams using ellipses. PLoS One 2014;9:e101717. doi:10.1371/ journal.pone.0101717.

25 Pi-Sunyer X, Blackburn G, Brancati FL, et al. Look AHEAD Research Group. Reduction in weight and cardiovascular disease risk factors in individuals with type 2 diabetes: one-year results of the look AHEAD trial. Diabetes Care 2007;30:1374-83. doi:10.2337/dc07-0048.

26 Whiting PF, Rutjes AW, Westwood ME, et al. QUADAS-2 Group. QUADAS-2: a revised tool for the quality assessment of diagnostic accuracy studies. Ann Intern Med 2011;155:529-36. doi:10.7326/0003-4819-155-8-201110180-00009.

27 Higgins JPT, Green Se. Cochrane Handbook for Systematic Reviews of Interventions Version 5.1.Cochrane Collaboration, 2011, www. handbook.cochrane.org.

28 Incani M, Sentinelli F, Perra L, et al. Glycated hemoglobin for the diagnosis of diabetes and prediabetes: Diagnostic impact on obese and lean subjects, and phenotypic characterization. J Diabetes Investig 2015;6:44-50. doi:10.1111/jdi.12241.

29 Guo F, Moellering DR, Garvey WT. Use of HbA1c for diagnoses of diabetes and prediabetes: comparison with diagnoses based on fasting and 2-hr glucose values and effects of gender, race, and age Metab Syndr Relat Disord 2014;12:258-68. doi:10.1089/ met.2013.0128

30 Wu S, Yi F, Zhou C, et al. HbA1c and the diagnosis of diabetes and prediabetes in a middle-aged and elderly Han population from northwest China (HbA1c). J Diabetes 2013;5:282-90. doi:10.1111/1753-0407.12035.

31 Lee H, Oh JY, Sung YA, et al. Optimal hemoglobin A1C Cutoff Value for Diagnosing type 2 diabetes mellitus in Korean adults. Diabetes Res Clin Pract 2013;99:231-6. doi:10.1016/j.diabres.2012.09.030.

32 Bhowmik B, Diep LM, Munir SB, et al. HbA(1c) as a diagnostic tool for diabetes and pre-diabetes: the Bangladesh experience. Diabet Med 2013;30:e70-7. doi:10.1111/dme.12088.

$33 \mathrm{Ma} \mathrm{H}, \mathrm{Gao}$ X, Lin HD, et al. Glycated haemoglobin in diagnosis of diabetes mellitus and pre-diabetes among middle-aged and elderly population: Shanghai Changfeng study. Biomed Environ Sci 2013;26:155-62.

34 Vlaar EM, Admiraal WM, Busschers WB, et al. Screening South Asians for type 2 diabetes and prediabetes: (1) comparing oral glucose tolerance and haemoglobin A1c test results and (2) comparing the two sets of metabolic profiles of individuals diagnosed with these two tests. BMC Endocr Disord 2013;13:8. doi:10.1186/1472-6823-13-8.

35 Bhansali A, Walia R, Ravi Kumar P, Ravi Kiran M, Shanmugasundar G. Accuracy of glycated haemoglobin in screening for pre-diabetes in Asian Indians--a community survey: the Chandigarh Urban Diabetes Study (CUDS). Diabet Med 2012;29:1385-9. doi:10.1111/i.1464-5491.2012.03634.x.

36 Tankova T, Chakarova N, Dakovska L, Atanassova I. Assessment of $\mathrm{HbA1} \mathrm{C}$ as a diagnostic tool in diabetes and prediabetes. Acta Diabetol 2012:49:371-8. doi:10.1007/s00592-011-0334-5.

37 Pinelli NR, Jantz AS, Martin ET, Jaber LA. Sensitivity and specificity of glycated hemoglobin as a diagnostic test for diabetes and prediabetes in Arabs. J Clin Endocrinol Metab 2011;96:E1680-3. doi:10.1210/jc.2011-1148.

38 Mostafa SA, Khunti K, Srinivasan BT, Webb D, Gray LJ, Davies MJ. The potential impact and optimal cut-points of using glycated haemoglobin, $\mathrm{HbA} 1 \mathrm{c}$, to detect people with impaired glucose regulation in a UK multi-ethnic cohort. Diabetes Res Clin Pract 2010;90:100-8. doi:10.1016/j.diabres.2010.06.008

39 Hu Y, Liu W, Chen Y, et al. Combined use of fasting plasma glucose and glycated hemoglobin A1c in the screening of diabetes and impaired glucose tolerance. Acta Diabetol 2010;47:231-6. doi:10.1007/ s00592-009-0143-2

40 Lorenzo C, Wagenknecht LE, Hanley AJ, Rewers MJ, Karter AJ, Haffner SM. A1C between 5.7 and $6.4 \%$ as a marker for identifying pre-diabetes, insulin sensitivity and secretion, and cardiovascular risk factors: the Insulin Resistance Atherosclerosis Study (IRAS). Diabetes Care 2010;33:2104-9. doi:10.2337/dc10-0679.
41 Mohan V, Vijayachandrika V, Gokulakrishnan K, et al. A1C cut points to define various glucose intolerance groups in Asian Indians. Diabetes Care 2010:33:515-9. doi:10.2337/dc09-1694.

42 Zhou XH, Ji LN, Luo YY, Zhang XY, Han XY, Qiao Q. Performance of $\mathrm{HbA}(1 \mathrm{c})$ for detecting newly diagnosed diabetes and pre-diabetes in Chinese communities living in Beijing. Diabet Med 2009;26:1262-8. doi:10.1111/j.1464-5491.2009.02831.x

43 Tanaka Y, Atsumi Y, Matsuoka K, et al. Usefulness of stable HbA(1c) for supportive marker to diagnose diabetes mellitus in Japanese subjects. Diabetes Res Clin Pract 2001;53:41-5. doi:10.1016 S0168-8227(01)00226-1.

44 Yoshinaga H, Kosaka K. High glycosylated hemoglobin levels increase the risk of progression to diabetes mellitus in subjects with glucose intolerance. Diabetes Res Clin Pract 1996;31:71-9. doi:10.1016/0168-8227(96)01195-3

45 Lin S, Hu L, Li X, et al. Glycated haemoglobin $A_{1}$ c for diagnosing diabetes in Chinese subjects over 50 years old: a community-based cross-sectional study. Clin Endocrinol (Oxf) 2014;80:656-61. doi:10.1111/cen.12202

46 Yang C, Liu Y, Li X, Liang H, liang X. Utility of hemoglobin A1c for the identification of individuals with diabetes and prediabetes in a Chinese high risk population. Scand J Clin Lab Invest 2012;72:403-9. doi:10.3109/00365513.2012.689324.

47 Tay TL, Foo JP, Tan EJH, et al. Body mass index (BMI) improves utility of glycated hemoglobin ( $\mathrm{HbA1C}$ ) as a screening tool for pre-diabetes. Journal of Diabetes Conference; April 2011; Madrid Spain: Wiley-Blackwell; 2011,111-2

48 Gingras V, Tchernof A, Weisnagel SJ, Robitaille J. Use of glycated hemoglobin and waist circumference for diabetic screening in women with a history of gestational diabetes. J Obstet Gynaecol Can 2013:35:810-5. doi:10.1016/S1701-2163(15)30837-9.

49 Katreddy MV, Pappachan JM, Taylor SE, Nevill AM, Indusekhar R, Nayak AU. Hemoglobin A1C in early postpartum screening of women with gestational diabetes. World J Diabetes 2013;4:76-81. doi:10.4239/ wjd.v4.i3.76.

50 Picón MJ, Murri M, Muñoz A, Fernández-García JC, Gomez-Huelgas R, Tinahones FJ. Hemoglobin A1c versus oral glucose tolerance test in postpartum diabetes screening. Diabetes Care 2012;35:1648-53. doi:10.2337/dc11-2111

51 Du T-T, Yin P, Zhang J-H, Zhang D, Shi W, Yu X-F. Comparison of the performance of $\mathrm{HbA} 1 \mathrm{c}$ and fasting plasma glucose in identifying dysglycaemic status in Chinese high-risk subjects. Clin Exp Pharmacol Physiol 2013;40:63-8. doi:10.1111/1440-1681.12038.

52 Kumaravel B, Bachmann MO, Murray N et al. University of East Anglia Impaired Fasting Glucose (UEA-IFG) Study Group. Use of haemoglobin A1c to detect impaired fasting glucose or Type 2 diabetes in a United Kingdom community based population. Diabetes Res Clin Pract 2012:96:211-6. doi:10.1016/j.diabres.2011.12.004

53 Kim C, Herman WH, Cheung NW, Gunderson EP, Richardson C. Comparison of hemoglobin A1c with fasting plasma glucose and 2-h postchallenge glucose for risk stratification among women with recent gestational diabetes mellitus. Diabetes Care 2011;34:1949-51. doi:10.2337/dc11-0269.

54 Sun X, Du T, Huo R, Yu X, Xu L. Impact of HbA1c criterion on the definition of glycemic component of the metabolic syndrome: the China health and nutrition survey 2009. BMC Public Health 2013;13:1045. doi:10.1186/1471-2458-13-1045.

55 Modan M, Halkin H, Karasik A, Lusky A. Effectiveness of glycosylated hemoglobin, fasting plasma glucose, and a single post load plasma glucose level in population screening for glucose intolerance. Am J Epidemiol 1984:119:431-44

56 Noctor E, Crowe C, Carmody LA, et al. ATLANTIC DIP investigators ATLANTIC DIP: simplifying the follow-up of women with previous gestational diabetes. Eur J Endocrinol 2013;169:681-7. doi:10.1530/ EJE-13-0491.

57 Noctor E, Crowe C, Avalos G, et al. Comparison of fasting plasma glucose and $\mathrm{HbA} 1 \mathrm{c}$ for follow-up of women with previous gestational diabetes. Irish Journal of Medical Science Conference: 37th Annual Meeting of the Irish Endocrine Society; Dublin Ireland. Springer; 2012, 181(S350).

58 Ihsan AB, Charles B, Raid B, Ali AY. Diagnostic accuracy of the American Diabetes Association criteria in the diagnosis of glucose intolerance among high-risk Omani subjects. Ann Saudi Med 2004;24:183-5.

59 Myers JE, Hasan X, Maresh MJ. Post-natal assessment of gestationa diabetes: fasting glucose or full glucose tolerance test?Diabet Med 2014;31:1133-7. doi:10.1111/dme.12503.

60 Mehmet S, Fincher S, Ibrahim S. NICE challenge on postnatal reclassification of glucose tolerance in women previously diagnosed with gestational diabetes mellitus. Pract Diabetes Int 2010;27:3468doi:10.1002/pdi.1521.

61 Holt RI, Goddard IR, Clarke P, Coleman MA. A postnatal fasting plasma glucose is useful in determining which women with gestational diabetes should undergo a postnatal oral glucose tolerance test. Diabet Med 2003;20:594-8. doi:10.1046/j.1464-5491.2003. 00974.x. 
62 McClean S, Farrar D, Kelly CA, Tuffnell DJ, Whitelaw DC. The importance of postpartum glucose tolerance testing after pregnancies complicated by gestational diabetes. Diabet Med 2010;27:650-4. doi:10.1111/j.1464-5491.2010.03001.x.

63 Kwong S, Mitchell RS, Senior PA, Chik CL. Postpartum diabetes screening: adherence rate and the performance of fasting plasma glucose versus oral glucose tolerance test. Diabetes Care 2009;32:2242-4. doi:10.2337/dc09-0900

64 Reinblatt SL, Morin L, Meltzer SJ. The importance of a postpartum $75 \mathrm{~g}$ oral glucose tolerance test in women with gestational diabetes. Obstet Gynaecol Can 2006;28:690-4. doi:10.1016/ S1701-2163(16)32230-7.

65 Agarwal MM, Punnose J, Dhatt GS. Gestational diabetes: implications of variation in post-partum follow-up criteria. Eur J Obstet Gynecol Reprod Biol 2004;113:149-53. doi:10.1016/j.ejogrb.2003.09.021.

66 Costa A, Carmona F, Martinez-Roman S, Quintó L, Levy I, Conget I. Post-partum reclassification of glucose tolerance in women previously diagnosed with gestational diabetes mellitus. Diabet Med 2000;17:595-8. doi:10.1046/j.1464-5491.2000.00341.x.

67 Conway DL, Langer 0 . Effects of new criteria for type 2 diabetes on the rate of postpartum glucose intolerance in women with gestational diabetes. Am J Obstet Gynecol 1999;181:610-4. doi:10.1016/ S0002-9378(99)70500-4.

68 Mudalige N, Thornhill L, Sinha S, Cotzias C, Dixit A.5.3 Postnatal Testing for persistence of abnormal glucose metabolism after Gestational Diabetes: Fasting Plasma Glucose or Oral Glucose Tolerance Test?Arch Dis Child Fetal Neonat Ed 2014;99(suppl 1):A4-A5. doi:10.1136/archdischild-2014-306576.12.

69 Venkataraman H, Crossman R, Tripathi G, Saravanan P. Can fasting plasma glucose (FPG) replace OGTT in diagnosing persisting postnatal abnormalities after GDM? Diabetes Conference: 74th Scientific Sessions of the American Diabetes Association. San Francisco, CA: American Diabetes Association.

70 Russell PWJ, Stanley K, Turner J, Temple R. The role of six week fasting plasma glucose in postpartum screening for persistent glucose metabolism impairment compared with the oral glucose tolerance test. Diabetic Medicine Conference: Diabetes UK Professional Conference 2013 Manchester, United Kingdom. Blackwell, 2013,187.

71 Joseph F, Photiou V, Verma A, Goenka N, Davies J, Clement-Jones M. et alldentifying women with persistent abnormal glucose metabolism following gestational diabetes mellitus: changing times, changing populations and changing needs. Br J Diabetes Vasc Dis 2013;13:31-6

72 Ko GT, Cockram CS, Chan JC. How to minimize missing those subjects with high 2HR plasma glucose but 'normal' fasting plasma glucose levels?) Med 2001;32:53-65.

73 Kakad R, Anwar A, Dyer P, Webber J, Dale J. Fasting plasma glucose is not sufficient to detect ongoing glucose intolerance after pregnancy complicated by gestational diabetes. Exp Clin Endocrinol Diabetes 2010;118:234-6. doi:10.1055/s-0029-1241876.

74 Cypryk K, Zawodniak-Szalapska M. Wilczynski J. Measurement of fasting glucose concentration is not useful as a screening test in women with previous gestational diabetes mellitus. Diabetologia Polska 2002:9:88-91.

75 James C, Bullard KM, Rolka DB, et al. Implications of alternative definitions of prediabetes for prevalence in U.S. adults. Diabetes Care 2011;34:387-91. doi:10.2337/dc10-1314

76 Zhang YH, Ma WJ, Thomas GN, et al. Diabetes and pre-diabetes as determined by glycated haemoglobin A1c and glucose levels in a developing southern Chinese population. PLoS One 2012;7:e37260. doi:10.1371/journal.pone.0037260.

77 Benaiges D, Chillaron JJ, Pedro-Botet J, et al. Role of A1c in the postpartum screening of women with gestational diabetes. Gynecol Endocrinol 2013;29:687-90. doi:10.3109/09513590.2013.788639.

78 Admiraal WM, Vlaar EM, Nierkens V, et al. Intensive lifestyle intervention in general practice to prevent type 2 diabetes among 18 to 60-year-old South Asians: 1-year effects on the weight status and metabolic profile of participants in a randomized controlled trial. PLoS One 2013;8:e68605. doi:10.1371/journal.pone.0068605.

79 Almeida FA, Shetterly S, Smith-Ray RL, Estabrooks PA. Reach and effectiveness of a weight loss intervention in patients with prediabetes in Colorado. Prev Chronic Dis 2010;7:A103.

80 Bernstein AM, Gendy G, Rudd N, et al. Management of prediabetes through lifestyle modification in overweight and obese AfricanAmerican women: the Fitness, Relaxation, and Eating to Stay Healthy (FRESH) randomized controlled trial. Public Health 2014;128:674-7. doi:10.1016/j.puhe.2014.04.005

81 Bhopal RS, Douglas A, Wallia S, et al. Effect of a lifestyle intervention on weight change in south Asian individuals in the UK at high risk of type 2 diabetes: a family-cluster randomised controlled trial. Lancet Diabetes Endocrinol 2014;2:218-27. doi:10.1016/ S2213-8587(13)70204-3.

82 Bouchard DR, Baillargeon JP, Gagnon C, Brown C, Langlois MF. Impac of health professionals' contact frequency on response to a lifestyle intervention with individuals at high risk for diabetes. Diabetes Res Clin Pract 2012;96:129-34. doi:10.1016/j.diabres.2011.12.019.
83 Burtscher M, Gatterer H, Kunczicky H, Brandstätter E, Ulmer H. Supervised exercise in patients with impaired fasting glucose: impact on exercise capacity. Clin J Sport Med 2009;19:394-8. doi:10.1097/ JSM.0b013e3181b8b6dc.

84 Chae JS, Kang R, Kwak JH, et al. Supervised exercise program, BMI, and risk of type 2 diabetes in subjects with normal or impaired fasting glucose. Diabetes Care 2012;35:1680-5. doi:10.2337/dc11-2074

85 Coles LT, Fletcher EA, Galbraith CE, Clifton PM. Patient freedom to choose a weight loss diet in the treatment of overweight and obesity: a randomized dietary intervention in type 2 diabetes and pre-diabetes. Int J Behav Nutr Phys Act 2014;11:64. doi:10.1186/1479-5868-11-64.

86 Davies MJ, Gray LJ, Troughton J, et al. Let’s Prevent Diabetes Team. A community based primary prevention programme for type 2 diabetes integrating identification and lifestyle intervention for prevention: the Let's Prevent Diabetes cluster randomised controlled trial. Prev Med 2016:84:48-56. doi:10.1016/i.ypmed.2015.12.012

87 Eriksson KF, Lindgärde F. Prevention of type 2 (non-insulindependent) diabetes mellitus by diet and physical exercise. The 6-year Malmö feasibility study. Diabetologia 1991;34:891-8. doi:10.1007/BF00400196.

88 Fontbonne A, Diouf I, Baccara-Dinet M, Eschwege E, Charles MA. Effects of 1-year treatment with metformin on metabolic and cardiovascular risk factors in non-diabetic upper-body obese subjects with mild glucose anomalies: a post-hoc analysis of the BIGPRO1 trial. Diabetes Metab 2009;35:385-91. doi:10.1016/j.diabet.2009.03.005.

89 Furber S, Monger C, Franco L, et al. The effectiveness of a brief intervention using a pedometer and step-recording diary in promoting physical activity in people diagnosed with type 2 diabetes or impaired glucose tolerance. Health Promot J Austr 2008;19:189-95.

90 Hegde SV, Adhikari P, Shetty S, Manirekar P, D’Souza V. Effect of community-based yoga intervention on oxidative stress and glycemic parameters in prediabetes: a randomized controlled trial. Complement TherMed 2013:21:571-6. doi:10.1016/j.ctim.2013.08.013.

91 Kang JY, Cho SW, Sung SH, Park YK, Paek YM, Choi TI. Effect of a continuous diabetes lifestyle intervention program on male workers in Korea. Diabetes Res Clin Pract 2010;90:26-33. doi:10.1016/j. diabres.2010.06.006.

92 Katula JA, Vitolins MZ, Morgan TM, et al. The Healthy Living Partnerships to Prevent Diabetes study: 2-year outcomes of a randomized controlled trial. Am J Prev Med 2013;44(Suppl 4):S324-32. doi:10.1016/j.amepre.2012.12.015

93 Koev D, Koeva L. Treatment of subjects with obesity and impaired fasting glucose with Metformin. Endocrinologia 2004:4:207-13.

94 Kosaka K, Noda M, Kuzuya T. Prevention of type 2 diabetes by lifestyle intervention: a Japanese trial in IGT males. Diabetes Res Clin Pract 2005;67:152-62. doi:10.1016/j.diabres.2004.06.010.

$95 \mathrm{Li}$ CL, Pan CY, Lu JM, et al. Effect of metformin on patients with impaired glucose tolerance. Diabet Med 1999;16:477-81. doi:10.1046/j.1464-5491.1999.00090.x.

96 Lindahl B, Nilssön TK, Borch-Johnsen K, et al. A randomized lifestyle intervention with 5-year follow-up in subjects with impaired glucose tolerance: pronounced short-term impact but long-term adherence problems. Scand I Public Health 2009;37:434-42. doi:10.1177/1403494808101373.

$97 \mathrm{Lu} \mathrm{YH}, \mathrm{Lu}$ JM, Wang SY, et al. Outcome of intensive integrated intervention in participants with impaired glucose regulation in China. Adv Ther 2011;28:511-9. doi:10.1007/s12325-011-0022-4.

98 McDermott KA, Rao MR, Nagarathna R, et al. A yoga intervention for type 2 diabetes risk reduction: a pilot randomized controlled trial. BMC ComplementAltern Med 2014:14:212. doi:10.1186/1472-6882-14-212

99 Moore SM, Hardie EA, Hackworth NJ, et al. Can the onset of type 2 diabetes be delayed by a group-based lifestyle intervention? A randomised control trial. Psychol Health 2011;26:485-99. doi:10.1080/08870440903548749.

100 Morey MC, Pieper CF, Edelman DE, et al. Enhanced fitness: a randomized controlled trial of the effects of home-based physical activity counseling on glycemic control in older adults with prediabetes mellitus. J Am Geriatr Soc 2012;60:1655-62. doi:10.1111/j.1532-5415.2012.04119.x

101 Oldroyd JC, Unwin NC, White M, Mathers JC, Alberti KG. Randomised controlled trial evaluating lifestyle interventions in people with impaired glucose tolerance. Diabetes Res Clin Pract 2006;72:117-27. doi:10.1016/j.diabres.2005.09.018.

102 Page RCL, Harnden KE, Cook JTE, Turner RC. Can life-styles of subjects with impaired glucose tolerance be changed? A feasibility study. Diabet Med 1992;9:562-6. doi:10.1111/j.1464-5491.1992.tb01839.x.

103 Pan X-R, Li GW, Hu Y-H, et al. Effects of diet and exercise in preventing NIDDM in people with impaired glucose tolerance. The Da Qing IGT and Diabetes Study. Diabetes Care 1997;20:537-44. doi:10.2337/ diacare.20.4.537.

104 Polovina S, Micić D. [The influence of diet with reduction in calorie intake on metabolic syndrome parameters in obese subjects with impaired glucose tolerance]Med Pregl 2010;63:465-9. doi:10.2298/ MPNS1008465P. 
105 Ramachandran A, Snehalatha C, Ram J, et al. Effectiveness of mobile phone messaging in prevention of type 2 diabetes by lifestyle modification in men in India: a prospective, parallel-group, randomised controlled trial. Lancet Diabetes Endocrinol 2013;1:191-8. doi:10.1016/S2213-8587(13)70067-6

106 Ramachandran A, Snehalatha C, Mary S, Mukesh B, Bhaskar AD, Vijay V. Indian Diabetes Prevention Programme (IDPP). The Indian Diabetes Prevention Programme shows that lifestyle modification and metformin prevent type 2 diabetes in Asian Indian subjects with impaired glucose tolerance (IDPP-1). Diabetologia 2006;49:289-97. doi:10.1007/s00125-005-0097-z

107 Roumen C, Corpeleijn E, Feskens EJM, Mensink M, Saris WHM, Blaak EE. Impact of 3-year lifestyle intervention on postprandial glucose metabolism: the SLIM study. Diabet Med 2008;25:597-605. doi:10.1111/j.1464-5491.2008.02417.x.

108 Saito T, Watanabe M, Nishida J, et al. Zensharen Study for Prevention of Lifestyle Diseases Group. Lifestyle modification and prevention of type 2 diabetes in overweight Japanese with impaired fasting glucose levels: a randomized controlled trial. Arch Intern Med 2011;171:1352 60. doi:10.1001/archinternmed.2011.275.

109 Sakane N, Sato J, Tsushita K, et al. Japan Diabetes Prevention Program (JDPP) Research Group. Prevention of type 2 diabetes in a primary healthcare setting: three-year results of lifestyle intervention in Japanese subjects with impaired glucose tolerance. BMC Public Health 2011;11:40. doi:10.1186/1471-2458-11-40.

110 Sakane N, Kotani K, Takahashi K, et al. Effects of telephone-delivered lifestyle support on the development of diabetes in participants at high risk of type 2 diabetes: J-DOIT1, a pragmatic cluster randomised trial. BMJ Open 2015;5:e007316. doi:10.1136/bmjopen-2014-007316.

111 Saslow LR, Kim S, Daubenmier JJ, et al. A randomized pilot trial of a moderate carbohydrate diet compared to a very low carbohydrate diet in overweight or obese individuals with type 2 diabetes mellitus or prediabetes. PLoS One 2014;9:e91027. doi:10.1371/journal. pone.0091027.

112 Tao L, Deng Y, Fan X, Bao Q-D. Effect of exercise training in patients with impaired glucose tolerance. Zhongguo Linchuang Kangfu 2004:28:2912-3.

113 Tuomilehto J, Lindström J, Eriksson JG, et al. Finnish Diabetes Prevention Study Group. Prevention of type 2 diabetes mellitus by changes in lifestyle among subjects with impaired glucose tolerance. N Engl J Med 2001;344:1343-50. doi:10.1056/ NEJM200105033441801

114 Watanabe M, Okayama A, Shimamoto K, Ueshima H. Short-term effectiveness of an individual counseling program for impaired fasting glucose and mild type 2 diabetes in Japan: a multi-center randomized control trial. Asia Pac J Clin Nutr 2007;16:489-97.

115 Xu DF, Sun JQ, Chen M, et al. Effects of lifestyle intervention and meal replacement on glycaemic and body-weight control in Chinese subjects with impaired glucose regulation: a 1-year randomised controlled trial. Br J Nutr 2013;109:487-92. doi:10.1017/ S0007114512001328.

116 Yates T, Davies M, Gorely T, Bull F, Khunti K. Effectiveness of a pragmatic education program designed to promote walking activity in individuals with impaired glucose tolerance: a randomized controlled trial. Diabetes Care 2009:32:1404-10. doi:10.2337/dc09-0130.

117 Ferrara A, Hedderson M, Albright CL, et al. A pregnancy and postpartum lifestyle intervention in women with gestational diabetes mellitus reduces diabetes risk factors: a feasibility randomized control trial. Diabetes Care 2011;34:1519-25. doi:10.2337/dc10-2221.

118 Ferrara A, Hedderson MM, Brown SD, et al. The Comparative Effectiveness of Diabetes Prevention Strategies to Reduce Postpartum Weight Retention in Women With Gestational Diabetes Mellitus: The Gestational Diabetes' Effects on Moms (GEM) Cluster Randomized Controlled Trial. Diabetes Care 2016;39:65-74. doi:10.2337/ dc15-1254.

119 Hu G, Tian H, Zhang F, et al. Tianjin Gestational Diabetes Mellitus Prevention Program: study design, methods, and 1-year interim report on the feasibility of lifestyle intervention program. Diabetes Res Clin Pract 2012;98:508-17. doi:10.1016/j.diabres.2012.09.015

$120 \mathrm{Kim}$ C, Draska M, Hess ML, Wilson EJ, Richardson CR. A web-based pedometer programme in women with a recent history of gestational diabetes. Diabet Med 2012;29:278-83. doi:10.1111/j.1464-5491.2011.03415.x

121 O'Reilly M, Avalos G, Dennedy MC, O'Sullivan EP, Dunne FP. Breast-feeding is associated with reduced postpartum maternal glucose intolerance after gestational diabetes. Ir Med / 2012;105(Suppl):31-6.

122 Pérez-Ferre N, Del Valle L, Torrejón M), et al. Diabetes mellitus and abnormal glucose tolerance development after gestational diabetes: A three-year, prospective, randomized, clinical-based, Mediterranean lifestyle interventional study with parallel groups. Clin Nutr 2015:34:579-85. doi:10.1016/i.clnu.2014.09.005.

123 Reinhardt JA, van der Ploeg HP, Grzegrzulka R, Timperley JG. Implementing lifestyle change through phone-based motivational interviewing in rural-based women with previous gestational diabetes mellitus. Health Promot / Austr 2012:23:5-9.
124 Shek NWM, Ngai CSW, Lee CP, Chan JYC, Lao TTH. Lifestyle modifications in the development of diabetes mellitus and metabolic syndrome in Chinese women who had gestational diabetes mellitus: a randomized interventional trial. Arch Gynecol Obstet 2014;289:31927. doi:10.1007/s00404-013-2971-0.

125 Shyam S, Arshad F, Abdul Ghani R, et al. Low glycaemic index diets improve glucose tolerance and body weight in women with previous history of gestational diabetes: a six months randomized trial. Nutr J 2013;12:68. doi:10.1186/1475-2891-12-68.

126 Penn L, White M, Oldroyd J, Walker M, Alberti KGM, Mathers JC. Prevention of type 2 diabetes in adults with impaired glucose tolerance: the European Diabetes Prevention RCT in Newcastle upon Tyne, UK. BMC Public Health 2009;9:342. doi:10.1186/1471-2458-9-342.

127 Li G, Zhang P, Wang J, et al. The long-term effect of lifestyle interventions to prevent diabetes in the China Da Qing Diabetes Prevention Study: a 20-year follow-up study. Lancet 2008:371:1783-9. doi:10.1016/S0140-6736(08)60766-7.

128 Knowler WC, Fowler SE, Hamman RF, et al. Diabetes Prevention Program Research Group. 10-year follow-up of diabetes incidence and weight loss in the Diabetes Prevention Program Outcomes Study. Lancet 2009;374:1677-86. doi:10.1016/S0140-6736(09)61457-4

129 Lindström J, Ilanne-Parikka P, Peltonen M, et al. Finnish Diabetes Prevention Study Group. Sustained reduction in the incidence of type 2 diabetes by lifestyle intervention: follow-up of the Finnish Diabetes Prevention Study. Lancet 2006;368:1673-9. doi:10.1016/ S0140-6736(06)69701-8

130 Diabetes Prevention Program Research Group. Long-term effects of lifestyle intervention or metformin on diabetes development and microvascular complications over 15-year follow-up: the Diabetes Prevention Program Outcomes Study. Lancet Diabetes Endocrinol 2015;3:866-75. doi:10.1016/S2213-8587(15)00291-0.

131 Herman WH, Ma Y, Uwaifo G, et al. Diabetes Prevention Program Research Group. Differences in $\mathrm{A} 1 \mathrm{C}$ by race and ethnicity among patients with impaired glucose tolerance in the Diabetes Prevention Program. Diabetes Care 2007;30:2453-7. doi:10.2337/dc06-2003.

132 KirkJK, Bell RA, Bertoni AG, et al. Ethnic disparities: control of glycemia, blood pressure, and LDL cholesterol among US adults with type 2 diabetes. Ann Pharmacother 2005;39:1489-501. doi:10.1345/ aph.1E685.

133 Likhari T, Gama R. Ethnic differences in glycated haemoglobin between white subjects and those of South Asian origin with normal glucose tolerance. J Clin Pathol 2010;63:278-80. doi:10.1136/ jсp.2009.065821.

134 Morris DH, Khunti K, Achana F, et al. Progression rates from $\mathrm{HbA} 1 \mathrm{C}$ 6.0-6.4\% and other prediabetes definitions to type 2 diabetes: a meta-analysis. Diabetologia 2013;56:1489-93. doi:10.1007/ s00125-013-2902-4.

135 Gerstein HC, Santaguida P, Raina P, et al. Annual incidence and relative risk of diabetes in people with various categories of dysglycemia: a systematic overview and meta-analysis of prospective studies. Diabetes Res Clin Pract 2007;78:305-12. doi:10.1016/j. diabres.2007.05.004

136 Zhang X, Gregg EW, Williamson DF, et al. A1C level and future risk of diabetes: a systematic review. Diabetes Care 2010;33:1665-73. doi:10.2337/dc09-1939.

137 Kim C, Newton KM, Knopp RH. Gestational diabetes and the incidence of type 2 diabetes: a systematic review. Diabetes Care 2002;25:1862 8. doi:10.2337/diacare.25.10.1862.

138 Edwardson CL, Gray LJ, Yates T, Barber SR, Khunti K, Davies MJ. Detection and early lifestyle intervention in those at risk of type 2 diabetes. Eur Med / 2014:2:48-57.

139 Ali MK, Echouffo-Tcheugui J, Williamson DF. How effective were lifestyle interventions in real-world settings that were modeled on the Diabetes Prevention Program?Health Aff (Millwood) 2012;31:67-75. doi:10.1377/hlthaff.2011.1009.

140 Dunkley AJ, Bodicoat DH, Greaves CJ, et al. Diabetes prevention in the real world: effectiveness of pragmatic lifestyle interventions for the prevention of type 2 diabetes and of the impact of adherence to guideline recommendations: a systematic review and meta-analysis. Diabetes Care 2014;37:922-33. doi:10.2337/dc13-2195.

141 Yates T, Khunti K, Bull F, Gorely T, Davies MJ. The role of physical activity in the management of impaired glucose tolerance: a systematic review. Diabetologia 2007;50:1116-26. doi:10.1007/ s00125-007-0638-8.

142 Balk EM, Earley A, Raman G, Avendano EA, Pittas AG, Remington PL. Combined diet and physical activity promotion programs to prevent type 2 diabetes among persons at increased risk: a systematic review for the Community Preventive Services Task Force. Ann Intern Med 2015;163:437-51. doi:10.7326/M15-0452.

143 Institute for Clinical and Economic Review. Diabetes Prevention Programs: Effectiveness and Value. Evidence Report.ICER, 2016.

144 Gillies CL, Abrams KR, Lambert PC, et al. Pharmacological and lifestyle interventions to prevent or delay type 2 diabetes in people with impaired glucose tolerance: systematic review and meta-analysis. BMJ 2007;334:299. doi:10.1136/bmj.39063.689375.55. 
145 Yamaoka K, Tango T. Efficacy of lifestyle education to prevent type 2 diabetes: a meta-analysis of randomized controlled trials. Diabetes Care 2005:28:2780-6. doi:10.2337/diacare.28.11.2780.

146 Ashra NB, Spong R, Carter P, et al. A systematic review and meta- analysis assessing the effectiveness of pragmatic lifestyle interventions for the prevention of type 2 diabetes mellitus in routine practice.Public Health England, 2015, https://www.gov.uk/government/publications/ diabetes-prevention-programmes-evidence-review.

147 Taylor J, Cottrell C, Chatterton H, et al. Identifying risk and preventing progression to Type 2 diabetes in vulnerable and disadvantaged adults: a pragmatic review. Diabet Med 2013;30:16-25. doi:10.1111/ dme.12027.

148 Yudkin IS, Montori VM. The epidemic of pre-diabetes: the medicine and the politics. BMJ 2014;349:g4485. doi:10.1136/bmj.g4485

149 Wareham NJ. Mind the gap: efficacy versus effectiveness of lifestyle interventions to prevent diabetes. Lancet Diabetes Endocrinol 2015:3:160-1. doi:10.1016/S2213-8587(15)70015-X

150 Tuomilehto J. Prevention of type 2 diabetes - where is the evidence?East Mediterr Health / 2014;20:677-8.

151 Hopper I, Billah B, Skiba M, Krum H. Prevention of diabetes and reduction in major cardiovascular events in studies of subjects with prediabetes: meta-analysis of randomised controlled clinical trials. Eur J Cardiovasc Prev Rehabil 2011;18:813-23. doi:10.1177/1741826711421687.

152 Uusitupa M, Peltonen M, Lindström J, et al. Finnish Diabetes Prevention Study Group. Ten-year mortality and cardiovascular morbidity in the Finnish Diabetes Prevention Study--secondary analysis of the randomized trial. PLoS One 2009;4:e5656. doi:10.1371/journal.pone.0005656.

153 World Health Organisation. Global status report on noncommunicable diseases 2014. http://www.who.int/nmh/publications/ncd-statusreport-2014/en/. WHO; 2014

154 loannidis JP. Why most clinical research is not useful. PLoS Med 2016;13:e1002049. doi:10.1371/journal.pmed.1002049.

155 Dunbar JA, Hernan AL, Janus ED, et al. Challenges of diabetes prevention in the real world: results and lessons from the Melbourne Diabetes Prevention Study. BMJ Open Diabetes Res Care 2015;3:e000131. doi:10.1136/bmjdrc-2015-000131.
156 Cornish F. Evidence synthesis in international development: a critique of systematic reviews and a pragmatist alternative. Anthropol Med 2015;22:263-77. doi:10.1080/13648470.2015.1077199.

157 Cooksey D. A review of UK health research funding. Stationery Office, 2006.

158 Barry E, Roberts S, Finer S, et al. Time to question the NHS diabetes prevention programme. BMJ 2015;351:h4717doi:10.1136/bmi.h4717

159 Nichter M. Representations that frame health and development policy. In: Nichter M, ed. Global Health: Why Cultural Perceptions, Social Representations and Biopolitics Matter Tuscon. University of Arizona Press, 2008: 107-18

160 Spencer Bonilla G, Rodriguez-Gutierrez R, M Montori V. What We Don’t Talk About When We Talk About Preventing Type 2 DiabetesAddressing Socioeconomic Disadvantage. JAMA Intern Med 2016;176:1053-4. doi:10.1001/jamainternmed.2016.2952.

161 Threlfall AG, Meah S, Fischer AJ, Cookson R, Rutter H, Kelly MP. The appraisal of public health interventions: the use of theory. J Public Health (Oxf) 2015;37:166-71. doi:10.1093/pubmed/ fdu044.

162 Rutter $\mathrm{H}$. The single most important intervention to tackle obesity... Int J Public Health 2012;57:657-8. doi:10.1007/s00038-0120385-6.

163 Kopelman P, Jebb SA, Butland B. Executive summary: Foresight 'tackling obesities: future choices' project. Obes Rev 2007;8(suppl 1);vi-ix. doi:10.1111/j.1467-789X.2007.00344.X

\section{Appendix 1: Search strategies}

Appendix 2: Adapted QUADAS2 Tool to assess quality of diagnostic accuracy studies

Appendix 3: Interventions to reduce the risk of developing diabetes methods and results tables Appendix 4: Diagnostic accuracy meta-analysis and prevalence analysis supplementary results 